\title{
A metastable brominated nanodiamond surface enables room temperature and catalysis-free amine chemistry
}

Cynthia Melendrez ${ }^{\Psi, \xi}$, Jorge A. Lopez-Rosas ${ }^{\Psi, \xi}$, Camron X. Stokes $^{\Psi, \xi}$, Tsz Ching Cheung ${ }^{\Psi}$, Sang-Jun Lee ${ }^{\Delta}$, Charles James Titus ${ }^{\Delta,}{ }$, Jocelyn Valenzuela, ${ }^{\Psi}$ Grace Jeanpierre ${ }^{\Psi}$, Halim Muhammad $^{\Psi}$, Polo Tran ${ }^{\Psi}$, Perla Jasmine Sandoval ${ }^{\Psi}$, Tyanna Supreme ${ }^{\Psi}$, Virginia Altoe ${ }^{\pi}$, Jan $\operatorname{Vavra}^{\Omega}$, Helena Raabova ${ }^{\Omega}$, Vaclav Vanek ${ }^{\Omega}$, Sami Sainio ${ }^{\Delta, \lambda}$, William B. Doriese ${ }^{\Sigma}$, Galen C. $\mathrm{O}^{\prime} \mathrm{Neil}^{\Sigma}$, Daniel S. Swetz ${ }^{\Sigma}$, Joel N. Ullom ${ }^{\Sigma}$, Kent $\operatorname{Irwin}^{\Delta, \Phi}$, Dennis Nordlund ${ }^{\Delta}$, Petr Cigler $^{\Omega} \&$ Abraham Wolcott ${ }^{\Psi, *}$

${ }^{\Psi}$ Department of Chemistry

San José State University

San José, CA 95192

${ }^{\pi}$ The Molecular Foundry

Lawrence Berkeley National Laboratory

1 Cyclotron Road Berkeley, CA

${ }^{\Omega}$ Institute of Organic Chemistry and Biochemistry

Academy of Sciences of the Czech Republic

Flemingovo nam. 2, 16610 Prague 6, Czech Republic

${ }^{\Delta}$ Stanford Synchrotron Radiation Lightsource

SLAC National Accelerator Laboratory

Menlo Park, CA 94025

${ }^{\Phi}$ Stanford University

Department of Physics

Palo Alto, CA 94025

${ }^{\lambda}$ University of Oulu

Microelectronics Research Unit

Faculty of Information Technology and Electrical

Engineering

Oulu, Finland

${ }^{\Sigma}$ Quantum Electromagnetics Division

National Institute of Standards and Technology

Boulder, CO 80305

* Corresponding authors: A. Wolcott (abraham.wolcott@sjsu.edu)

$\xi$ equal contributions 


\begin{abstract}
Bromination of high-pressure high-temperature (HPHT) nanodiamond (ND) surfaces has not been explored and can open new avenues for increased chemical reactivity and diamond lattice covalent bond formation. The large bond dissociation energy of the diamond lattice-oxygen bond is a challenge that prevents new bonds from forming and most researchers simply use oxygenterminated ND (alcohols and acids) as a reactive species. In this work, we transformed a tertiary alcohol-rich ND surface to an amine surface with $~ 50 \%$ surface coverage and was limited by the initial rate of bromination. We observed that alkyl-bromide moieties are highly labile on NDs and are metastable as previously found using density functional theory. The instability of the bromine terminated ND is explained by steric hindrance and poor surface energy stabilization. The strong leaving group properties of the alkyl-bromide intermediate were found to form diamond-nitrogen bonds at room temperature and without catalysts. The chemical lability of the brominated ND surface led to efficient amination with $\mathrm{NH}_{3} \bullet \mathrm{THF}$ at $298 \mathrm{~K}$, and a catalyst-free Sonogashira-type reaction with an alkyne-amine produced an 11-fold increase in amination rate. Overlapping spectroscopies under inert, temperature-dependent and open-air conditions provided unambiguous chemical assignments. Amine-terminated NDs and folic acid were conjugated using sulfoNHS/EDC coupling reagents to form amide bonds, confirming that standard amine chemistry remains viable. This work supports that a robust pathway exists to activate a chemically inert diamond surface at room temperature, which broadens the pathways of bond formation when a reactive alkyl-bromide surface is prepared. The unique surface properties of brominated and aminated nanodiamond reported here are impactful to researchers who wish to chemically tune diamond for quantum sensing applications or as an electron source for chemical transformations.
\end{abstract}




\section{Introduction}

The addition of bromine to small molecules, macromolecules and carbon nanomaterials typically includes a bromine source such as $\mathrm{Br}_{2}, \mathrm{HBr}$ or $N$-bromosuccinimide and can lead to bromine bonds with $\mathrm{sp}^{3}$ - or $\mathrm{sp}^{2}$-hybridized carbon atoms. Bromine bound to carbon serves as a good leaving group and enables a catalog of reactions to be performed. ${ }^{1}$ Powerful demonstrations include Ullman coupling and Sonogashira reactions that use the enhanced leaving group properties of halogens in general and bromine in particular to form new chemical transformations. ${ }^{2,3}$ The synthesis of highly ordered nanoarchitectures with halogenated porphyrin rings takes advantage of the temperature-dependent dissociation of iodine and bromine to direct assembly on metal surfaces with a high level of fidelity. ${ }^{4,5}$ Bromine-functionalized graphene and carbon nanotubes have allowed robust chemical routes to be used for band engineering and sensing applications. ${ }^{6-9}$ In contrast, bromination on the surface of bulk diamond and detonation nanodiamonds (NDs) has not been widely explored - for good reason. ${ }^{10,11}$ Bromine has an atomic radius of $112 \mathrm{pm}^{12}$, which is large compared to the densely packed facet of the 111 diamond surface with 18 atoms $/ \mathrm{nm}^{2}$. $^{13}$ For that reason, bromination of $\mathrm{Si}$ and Ge is more common due to the increase in crystal lattice spacing and decreased steric hindrance. ${ }^{14-16}$ One previous bromination protocol was used with detonation NDs and was not well detailed, and the handling was performed largely under open-air conditions and in the presence of water for purification. ${ }^{17}$ In this work, we show the following: alkyl bromide formation on high-pressure high-temperature (HPHT) NDs is possible using thionyl bromide $\left(\mathrm{SOBr}_{2}\right)$, it displays enhanced chemical reactivity compared to that of brominated small molecule analogs and the reaction products must be carefully handled under inert conditions to retain alkyl bromide moieties. This work addresses the difficulty in chemically activating HPHT ND surfaces, provides a new platform for atomic and molecular control and will be of interest to researchers using diamond and other ultrahard materials for quantum sensing applications. ${ }^{18-20}$

Understanding this work is based on the knowledge that open-air aerobic oxidation of HPHT ND powders results in alcohol (hydroxyl) groups terminating the surface in a fashion similar to that for bulk diamond on the $\{111\}$ facet and not carboxylic acid termination as found on detonation NDs. ${ }^{21,22}$ Alcohol termination of bulk diamond is widely accepted within the diamond research community, but this fact has not been widely accepted by researchers studying HPHT NDs. Kono, Wang and Loh discuss and reference evidence for alcohol termination on bulk diamond based on surface energy, crystallographic structure and sterics. ${ }^{23-25}$ This conclusion is supported by spectroscopic data and is rationalized by the understanding that the $\{111\}$ facet is predominantly exposed in HPHT NDs due to ball milling. Similar to bulk diamond, $\{111\}$ facets are single dangling bond surfaces and may form one $\mathrm{sp}^{3}$-hybridized bond per surface carbon atom. ${ }^{26}$ HPHT and detonation NDs do not have the the same surface termination after aerobic oxidation and must be addressed separately. The differences between HPHT and detonation NDs are a result of the production method, their resultant surface-to-volume ratio and exposed crystallographic facets. HPHT NDs of 30-100 $\mathrm{nm}$ are produced in a top-down approach through ball milling of bulk single-crystal diamonds by manufacturers such as Microdiamant (Switzerland) and are commercially sold for polishing applications. ${ }^{27}$ Ball milling predominantly cleaves the $\{111\}$ crystallographic planes based on facet strength and in turn exposes the single dangling bond surface. ${ }^{28}$ The dangling $\mathrm{sp}^{3}$ bond can then support alcohol bond formation during aerobic oxidation, as seen in bulk 111 terminated diamond. ${ }^{26}$ In handling bulk diamond, a jeweler cleaves a rough diamond stone along the (111) direction to produce a well-cleaved diamond, and this 
phenomenon has been empirically known for centuries. ${ }^{29}$ Density functional theory (DFT) calculations by Telling clearly showed that diamond cleavage proceeds as a function of strain from $\{111\} \rightarrow\{110\} \rightarrow\{100\}$ with maximum strengths of $90 \mathrm{GPa}, 130 \mathrm{GPa}$ and $225 \mathrm{GPa}$, respectively, and is caused by strength anisotropy. ${ }^{30}$ Electron microscopy of 30-100 nm HPHT NDs has verified the cleavage process, with irregularly shaped particles that resemble shards of broken crystallites. ${ }^{31}$ In contrast, detonation NDs are produced through a bottom-up approach wherein hexogen or trinitrotoluene (TNT) is ignited in stainless steel vessels, resulting in faceted spherical particles with diameters of $\sim 5 \mathrm{~nm} .{ }^{32}$ Detonation NDs have a larger surface area $\left(270-315 \mathrm{~m}^{2} / \mathrm{g}\right)^{33}$ than HPHT NDs $\left(57-140 \mathrm{~m}^{2} / \mathrm{mg}\right)$, a diverse range of carbon-oxygen moieties from ethers to acid anhydrides ${ }^{34}$ and a high concentration of $\mathrm{sp}^{2}$ groups formed by dangling bonds,${ }^{35}$ as confirmed via Raman spectroscopy. ${ }^{36}$

In most settings where surface control is required, HPHT NDs (ranging from 30-100 nm) are first aerobically oxidized to remove amorphous carbon from the surface and produce an alcohol-rich surface (ND-OH) ${ }^{22}$ Chemical modification of the tertiary alcohol surface is a critical step for the construction of functional sensors using nitrogen vacancy centers (NVCs) or as a catalytic substrate, but modifying or removing the $\mathrm{C}-\mathrm{O}-\mathrm{H}$ bonds is challenging. The difficulty in modifying oxidized diamond surfaces is due to the large carbon-oxygen bond dissociation energies $(1442 \mathrm{~kJ} / \mathrm{mol})^{37}$, high atomic surface density $\left(18.2\right.$ atoms $/ \mathrm{nm}^{2}$ on the 111 facet $)$ and steric hindrance. In contrast, chemical modifications of detonation NDs typically target surface carboxylate groups via amidic coupling or reactive $\mathrm{sp}^{2}$ structures, which can be created by thermal annealing of detonation NDs. Much work has been accomplished with the more reactive $5 \mathrm{~nm}$ detonation materials and has been reviewed thoroughly. ${ }^{32,34,38}$ HPHT NDs can be converted from tertiary alcohols to carboxylic acids with acid-base-acid chemistry and provides a pathway for surface linking chemistry; ${ }^{39}$ however, the surface density of carboxylic acids can reach only a few percent of the surface carbon atoms and is inhomogeneous. ${ }^{40}$ Growth of silica $\left(\mathrm{SiO}_{2}\right)$ shells on ND cores is a demonstrated route for chemical modification of HPHT NDs, and background-free cellular imaging, real-time magnetic sensing and coating with tailored lipidic bilayers have been demonstrated. ${ }^{41-44}$ With silica shell growth, the carbon-oxygen groups are not removed from the diamond surface but instead used to form a priming layer to generate silica growth in a modified Stöber method.

For long-term advancements with HPHT NDs and ultra-dense materials such as silicon carbide, we frame this work as important because a reactive surface intermediate is prepared at room temperature and could be used for any nucleophilic species to generate new diamond lattice covalent bonds. Direct amine bond formation of HPHT NDs has not been demonstrated and is a clear example of a useful surface termination approach for biolabeling applications due to the enhanced reactivity of amines. Previously, direct bulk diamond lattice-nitrogen bond formation is limited; for example, Stacey and coworkers used nitrogen-rich plasma treatment to terminate (001) diamond surfaces and produced a N-N-rich surface. ${ }^{45}$ Although these surfaces are expected to induce a positive electron affinity, they left behind minimal surface states within the bandgap and allowed the near-surface carbon atoms to exhibit bulk-like electronic states. In a related study, Sotowa et al. used gas phase hydrogenation, chlorination and amination chemistry of diamond powders in a tube furnace but yielded low carbon-nitrogen bonding rates that were dominated by the formation of imines and not amines. ${ }^{46}$ Zhu and Hamers converted hydrogen-terminated bulk diamond to an amine-terminated form using ammonia plasma and further established a negative 
electron affinity surface similar to hydrogen terminated diamond. ${ }^{47}$ Simple wet chemistry of oxidized HPHT NDs with bromine and amine termination can open unique pathways for low-cost chemical transformations, surface dipole engineering, NVC sensing and as a source of solvated electrons for chemistry. ${ }^{48-50}$

Here, we demonstrate that room temperature and catalysis-free diamond lattice-to-nitrogen bond formation of aerobically oxidized HPHT NDs is possible through a highly labile alkyl bromide (ND-Br) intermediate. Surface analysis of the NDs revealed that $\sim 50 \%$ of the surface carbon atoms were aminated, and is due to the upper limit of bromine termination previously described by DFT. ${ }^{51}$ We describe a reaction pathway that chemically activates the ND-OH, converting the alcohol groups to alkyl bromides; moreover, we found that the ND-Br surfaces have enhanced reactivity and that debromination occurs within seconds under open-air conditions and at $90^{\circ} \mathrm{C}$ under inert conditions. Debromination under open-air conditions did not immediately yield new alcohol groups, suggesting that a long-lived "radical carbon" or other intermediate is present at the ND surface. Generating amine bonds on the diamond lattice is motivated by the enhanced reactivity of amines, the vast library of chemical modifications based on amines and their negative electron affinity surface. Conjugation of $\mathrm{ND}-\mathrm{NH}_{3}$ with folic acid to form amide bonds was performed, which established that reaction of these amine groups with small molecules was successful. By using mild nucleophiles (amines), we show that reactions with ND-Br under conditions at $25^{\circ} \mathrm{C}$ and without catalysts are possible. Additionally, a reaction of ND-Br and propargylamine yielded a polyimine-coated ND core via a Sonogashira-type reaction and an 11fold increase in the nitrogen content. With these reactive ND-Br constructs, researchers in chemistry, bioengineering and materials science could use a catalogue of nucleophiles to generate new diamond-heteroatom bonds. Robust chemical and electronic structure analysis of the NDs using overlapping spectroscopic techniques under inert, temperature-dependent and open-air conditions provided definitive characterization. This new surface pathway will likely be impactful for researchers using nanoscale diamonds with nitrogen vacancy centers (NVCs) for quantum sensing and biolabeling.

\section{Results and Discussion}

Hydrophilic ND-OH surface and water desorption via TPD-DRIFTS. Key spectroscopic features of aerobically oxidized $\mathrm{ND}-\mathrm{OH}$ can yield important information about hydrophilicity/hydrophobicity and the preparation of ND constructs prior to bromination chemistry. Aerobic oxidation of HPHT NDs rendered the 30-50 nm ND-OH particles hydrophilic and tannish in color after removal of dark amorphous carbon. Diffuse reflectance infrared Fourier transform spectroscopy (DRIFTS) provided surface vibrational modes of the ND-OH samples under open-air, inert atmosphere and temperature-dependent conditions. ND-OH samples have a pronounced peak at $1105 \mathrm{~cm}^{-1}$ assigned to the $(\mathrm{C}-\mathrm{O})_{v}$ band of tertiary alcohols, the bending mode of adsorbed water $(\mathrm{O}-\mathrm{H})_{\delta}$ at $\sim 1630 \mathrm{~cm}^{-1}$, a carboxylic acid peak at $1780 \mathrm{~cm}^{-1}$ and a broad $\mathrm{O}-\mathrm{H}$ stretching band $(\mathrm{O}-\mathrm{H})_{v}$ at $3000-3500 \mathrm{~cm}^{-1}$ due to adsorbed water and alcohol groups (Figure 1A). Using Kubelka-Munk transforms, we estimate that there are $\sim 15: 1$ alcohol groups for each carboxylic acid observed after oxidation at $525^{\circ} \mathrm{C}$ for 5 hours, and this ratio can be estimated via integration and the available extinction coefficients of tertiary alcohols and carboxylic acids from NIST. ${ }^{22,} 52$ Previous work on HPHT NDs mistakenly assigned the $1630 \mathrm{~cm}^{-1}$ peak to C=Ocontaining groups such as ketones, and we wished to clarify that this feature is not due to oxygen- 
terminated diamond ${ }^{53}$ We confirmed the decrease of the adsorbed water spectral component at $1630 \mathrm{~cm}^{-1}$ via temperature programmed desorption (TPD)-DRIFTS at $25,100,200$ and $300^{\circ} \mathrm{C}$ under open-air conditions. The observed water stretching band and bending mode simultaneously decreased as expected when water left the surface, and the stretching modes of $(\mathrm{C}-\mathrm{O})_{v}$ and $(\mathrm{C}=\mathrm{O})_{v}$ on the ND-OH surface remained (Figure 1A). The quantitative removal of adsorbed water was found to be $72 \%, 97 \%$ and $100 \%$ at $100^{\circ} \mathrm{C}, 200^{\circ} \mathrm{C}$ and $300^{\circ} \mathrm{C}$, respectively. Here, the $1630 \mathrm{~cm}^{-1}$ peak was used as a quantifiable signature for the dryness of our samples prior to bromination chemistry with $\mathrm{SOBr}_{2}$. During DRIFTS data collection, the observation of the adsorbed water band is a key metric in determining the hydrophilicity, hydrophobicity and adsorbed water content during bromination and amination reactions. The materials and procedures of all samples are detailed in the Supporting Information (SI) and show ND-OH, ND-Br and $\mathrm{ND}-\mathrm{NH}_{3}$ sample preparation.

Synthesis and inert DRIFTS characterization of ND-Br. The conversion of ND-OH (tertiary alcohols) to ND-Br (alkyl-bromide terminated) constructs was accomplished with $\mathrm{SOBr}_{2}$ at room temperature, wherein the diamond lattice bromine bond is likely formed via an $\mathrm{S}_{\mathrm{N}} 1$ (substitution type 1) mechanism and the addition of pyridine increases the ND-Br rate (see SOM3 for a mechanism, materials and procedures). ND-Br formation was confirmed with a strong doublet peak arising at $750 \mathrm{~cm}^{-1}$ due to the $(\mathrm{C}-\mathrm{Br})_{v}$ stretching mode (Figure 1B), which was in a region that was vibrationally silent in ND-OH. Mechanistically (see SOM3 in SI), ND-Br reactions with $\mathrm{SOBr}_{2}$ can proceed via a bromosulfite ether intermediate, a release of bromide ions via pyridine nucleophilic attack and finally carbocation intermediate formation, resulting in nucleophilic attack by $\mathrm{Br}^{-}$on the diamond surface. Bromination of diamond with an $\mathrm{S}_{\mathrm{N}} 2$ (substitution type 2) mechanism would not be possible due to the saturation of all carbon-carbon bonds in the diamond subsurface and therefore should follow an $\mathrm{S}_{\mathrm{N}} 1$ mechanism during bromination with a carbocation intermediate. The mechanism depicted in SOM2 is hypothetical and depicts the most likely route for bromination. ND-Br bond formation proceeded without pyridine within 24 hours, with easier purification and a lower ND-Br yield (Figure 1B/C and SOM2 in SI). The use of pyridine produced a viscous side product of pyridinium perbromide $\left(\mathrm{NC}_{5} \mathrm{H}_{5} \bullet \mathrm{HBr} \bullet \mathrm{Br}_{2}\right)$, which was removed with a dimethyl sulfoxide (DMSO) washing step. An increased rate of ND-Br formation with pyridine was observed when comparing 2-hour and 24-hour reactions and tracking the emergence of the $(\mathrm{C}-\mathrm{Br})_{v}$ stretching mode at $750 \mathrm{~cm}^{-1}$ (SOM3 in SI). The champion ND-Br sample (orange trace in Figure 1C) was produced after only a single washing step and remained stable for 24 hours, and the $(\mathrm{C}-\mathrm{Br})_{v}$ signal at $750 \mathrm{~cm}^{-1}$ dominated the spectra. The champion ND-Br sample lacks reproducibility due to instability associated with an increased level of bromination, which is under investigation.

There is evidence of a unique intracrystallite Williamson ether-like reaction occurring as a byproduct of the reaction of alkyl bromides and alcohols adjacent to one another on the diamond surface. Significant surface features are modified after the bromination reaction, including complete removal of the $(\mathrm{O}-\mathrm{H})_{v}$ band at $3000-3500 \mathrm{~cm}^{-1}$ from adsorbed water and removal of alcohol groups. While desorption of water was predicted due to desiccating the sample prior to bromination, the elimination of alcohol $(\mathrm{C}-\mathrm{O}-\mathrm{H})$ groups was unexpected and suggested that ether functionalities $(\mathrm{C}-\mathrm{O}-\mathrm{C})$ were formed during the $\mathrm{SOBr}_{2}$ treatment through a substitution reaction. The formation of ethers is traditionally understood to proceed by an intramolecular Williamsontype ether rearrangement whereby an alkoxide reacts with an alkyl halide to yield an ether. ${ }^{54,55}$ 
Based on that understanding, ether bridges would be formed by adjacent alcohols reacting with nearest neighbor alkyl bromides along with the formation of $\mathrm{HBr}$ (see SOM2 for mechanistic details). The evidence includes the emergence of a peak at $\sim 1025 \mathrm{~cm}^{-1}$ after bromination, which we assign to the $(\mathrm{C}-\mathrm{O}-\mathrm{C})_{v}$ stretching mode and lack of $(\mathrm{O}-\mathrm{H})_{v}$ signal from alcohols at $\sim 3200 \mathrm{~cm}^{-}$ 1 ; however, the details of the chemical kinetics and quantification are beyond the scope of this letter.

Confirmation of alkyl bromides and surface coverage. X-ray photoelectron spectroscopy (XPS), a surface-sensitive and element-specific technique confirmed the transition from an alcohol-rich surface to an alkyl bromide-terminated surface, in agreement with our DRIFTS results. An inert transfer module was used for all XPS data to ensure the retention of alkyl-bromide termination and eliminate $\mathrm{H}_{2} \mathrm{O}$ and $\mathrm{O}_{2}$ exposure. The C1s XPS data of ND-OH showed peaks at $284.5 \mathrm{eV}, 286.5 \mathrm{eV}$ and $288.5 \mathrm{eV}$, which were assigned to bulk diamond (C-C), alcohols (C-O) and carboxylic acids $(\mathrm{COOH})$, respectively (Figure 2A). Previous quantitative analysis has shown the alcohol-to-carboxylate ratio to be $\sim 15: 1$, suggesting that $\mathrm{SOBr} 2$ reacts primarily with hydroxyl moieties on the diamond surface, in agreement with the DRIFTS results. ${ }^{22}$ ND-OH treated with $\mathrm{SOBr}_{2}$ produced an ND-Br construct that exhibited convolved features attributable to the $(\mathrm{C}-\mathrm{C})$, $(\mathrm{C}-\mathrm{Br})$ and $(\mathrm{C}-\mathrm{O})$ bonding environments at $284.5 \mathrm{eV}, 286.0 \mathrm{eV}$ and $286.5 \mathrm{eV}$, respectively. We interpret the results as being consistent with a partially brominated surface that retains either alcohol or ether moieties due to the intracrystallite Williamson ether-like reaction. Br3d XPS spectra confirmed alkyl bromide formation with convolution of the $\mathrm{Br} 3 \mathrm{~d}_{3 / 2}$ and $\mathrm{Br} 3 \mathrm{~d}_{5 / 2}$ spin states at $70.0 \mathrm{eV}$ and $69.0 \mathrm{eV}$, respectively, with an energy difference of $\sim 1.0 \mathrm{eV}$ and a ratio of $0.6 \mathrm{eV}$ (Figure 2B). ${ }^{56} \mathrm{SOBr}_{2}$ with pyridine from $2 \rightarrow 24$-hour reaction times showed an increased $\mathrm{Br} 3 \mathrm{~d}$ signal, and peak positions remained consistent at 69.0 and $70.0 \mathrm{eV}$ indicating no change in bonding environment (Figure 1B, 2B and SOM3). The addition of pyridine plays two active roles: harvesting protons generated during the nucleophilic attack of the alcohol moiety on the sulfur center and activating the release of bromide ions from the intermediate bromosulfite ester complex bound to the diamond surface. The XPS and DRIFTS data indicate that the rate of alkyl bromide formation increased by $\sim 60 \%$ over the course of the reaction with pyridine.

The quantification of surface groups is based on a model in which all C1s XPS signals are from diamond with an inelastic mean free path of approximately $1.87 \mathrm{~nm}$ and where the N1s, O1s and $\mathrm{Br} 3 \mathrm{~d}$ signals originate from only the surface moieties. Based on analysis of the XPS survey scans, inelastic mean free electron escape depths of $\mathrm{C}, \mathrm{N}, \mathrm{O}$ and $\mathrm{Br}$ photoelectrons and their respective ionization cross sections, we estimate that $36-52 \%$ of all surface sites were brominated in examining 3 different samples (section 4 in SI). Br3d XPS data of ND-Br samples were originally underestimated due to spontaneous debromination after synthesis and debromination under ultrahigh vacuum conditions. A typical survey scan with a Tougaard background of ND-Br showed $\mathrm{C} 1 \mathrm{~s}, \mathrm{O} 1 \mathrm{~s}$ and $\mathrm{Br} 3 \mathrm{~d}$ atomic percentages of $73 \%, 23.5 \%$ and $2.5 \%$, respectively. When originally modeling the surface termination with a 111 facet $\left(18.2\right.$ atoms $/ \mathrm{nm}^{2}$ ), we calculated that $\sim 3 \mathrm{C}-\mathrm{Br}$ bonds $/ \mathrm{nm}^{2}$ were formed, and without the addition of pyridine, the bromination reached $0.5 \%$ or $0.6 \mathrm{C}-\mathrm{Br}$ bonds $/ \mathrm{nm}^{2}$. The bromination rates were corrected when considering the yield of $\mathrm{C}-\mathrm{N}$ bond formation that proceeds after successful bromination. Based on the nitrogen atomic percentage of 5.4-7.8\% after amination chemistry and a 1:1 alkyl-bromide $\rightarrow$ amine mechanism, we conclude that Br levels of 36-52\% were achieved (Tables 2 and 3 in SI). The bromination of $36-52 \%$ of the surface sites reached the maximum of $50 \%$ predicted by Tiwari, yet these DFT 
calculations did not account for the intracrystallite surface chemistry of the Williamson ether-like reaction. ${ }^{51}$ Previous DFT calculations showed that the addition of bromine atoms to a clean Cterminated (001)-(2x1) surface at 50\% coverage had an adsorption energy of $1.82 \mathrm{eV} /$ atom, which was lower than that for the addition of hydrogen, fluorine and chlorine across a (111)-(1x1) surface, with $2.17 \mathrm{eV} /$ atom, $4.72 \mathrm{eV} /$ atom and $2.22 \mathrm{eV}$ /atom, respectively. ${ }^{51,57}$ Lower bromination rates are predicted in comparison to those with hydrogen $(31 \mathrm{pm})$, fluorine $(64 \mathrm{pm})$ and chlorine $(97 \mathrm{pm})$ due to the large atomic radii of bromine (112 pm). For comparison, the C-H, C-F, C-Cl and $\mathrm{C}-\mathrm{Br}$ bond distances on diamond were calculated to be $110 \mathrm{pm}, 136 \mathrm{pm}, 171 \mathrm{pm} 192 \mathrm{pm}$, respectively. ${ }^{51,57}$ It should be noted that the bromine termination study by Tiwari was carried out on (001) surfaces, yet the same authors also conducted the earlier hydrogen, fluorine and chlorine termination study with (111) and showed they were consistent when calculating surface coverage, adsorption energies and bond distance. Our experimental evidence of the upper limits of ND-Br coverage are well supported theoretically with DFT.

Diamond-bromine bond dissociation studies in open air. The ND-Br samples exposed to air resulted in fast alkyl-bromide dissociation, representing potential evidence of a "radical carbon" on the diamond 111 surface. ${ }^{58}$ The ND-Br surface is extremely labile in comparison to that of many brominated substrates, including 1-bromoadamantane. Instantaneous debromination of ND$\mathrm{Br}$ under open-air conditions at $25^{\circ} \mathrm{C}$ was tracked with DRIFTS and showed a $\mathrm{t}_{1 / 2}$ value of $\sim 12$ minutes when air was allowed into an inert atmosphere DRIFTS chamber (section 2 in SI). Alkyl bromide dissociation was found to have pseudo-first-order kinetics of $\mathrm{k}^{\prime}=7.67^{*} 10^{-7} 1 / \mathrm{s}$ based on the local relative humidity at the time of the experiments. During the 80 -minute experiment, there was no evidence that the diamond surface formed new alcohols, as no increase in the $1105 \mathrm{~cm}^{-1}$ peak was observed. Notably, the $(\mathrm{Br}-\mathrm{C}=\mathrm{O})_{v}$ mode at $1815 \mathrm{~cm}^{-1}$, which shifted $35 \mathrm{~cm}^{-1}$ from its nominal $(\mathrm{C}=\mathrm{O})_{v}$ position, did not change during the air exposure study. We hypothesize that sterically unhindered acid bromides at edges and defect sites are more stable than alkyl bromides. Alkyl bromides are sterically hindered and energetically destabilizing on the diamond facets as calculated by DFT; therefore, acid bromides did not readily undergo debromination during these air exposure experiments.

The prediction of a carbocation-like state with brominated diamond was described by Larsson and Lunell in 1997. ${ }^{58}$ Their DFT calculations showed a surface bond angle of $112.9^{\circ}$ that was interpreted as having $\mathrm{sp}^{2}$ character and described as a "radical carbon." We interpret our findings as a possible conformation of this unique bonding environment found on brominated diamond. For small molecules, an analogous system would be that of 8,9-dehydro-2-adamantyl with a stable carbocation at $-120^{\circ} \mathrm{C}$, as confirmed via ${ }^{1} \mathrm{H}$ and ${ }^{13} \mathrm{C}$ nuclear magnetic resonance (NMR) spectroscopy. ${ }^{59}$ However, tracking carbocations with solution or solid-state NMR techniques is not possible due to the lack of sensitivity of NMR spectroscopy to trace surface groups on HPHT ND surfaces. The lability of the $\mathrm{C}-\mathrm{Br}$ bond, the unique properties of diamond and the low concentration of water molecules under atmospheric conditions have aided this finding. Based on these observations and analysis, the conclusion is that rehydroxylation is slow compared to the debromination kinetics at $60 \%$ relative humidity and $25^{\circ} \mathrm{C}$. The debromination side products are likely $\mathrm{HBr}$ and $\mathrm{Br}_{2}$, but were not analyzed as the ND surface structure was our primary focus. To test the rehydroxylation kinetics of ND-Br, we reacted the ND-Br samples with $18 \mathrm{M} \Omega$ water [55.5 M] for 1 minute, purified by centrifugation and probed with DRIFTS and found the reemergence of an alcohol-rich surface within the 1-minute reaction time (SOM5 in SI). The 
pseudo-first-order rate was calculated to be $\mathrm{k}^{\prime}=0.0551 / \mathrm{s}$ with neat water, an increase of $7.2 * 10^{4}$ in reaction rate, and we estimate that the rehydroxylation reaction is complete in approximately 66 ms under these conditions.

Direct catalyst-free amine formation at room temperature. Demonstration of amine insertion via nucleophilic attack of $\mathrm{ND}-\mathrm{Br}$ was accomplished at room temperature using ammonia in tetrahydrofuran $\left(\mathrm{NH}_{3} \bullet \mathrm{THF}\right)$ and was found to convert all brominated surface species. The use of $\mathrm{NH}_{3} \bullet$ THF is rationalized to ensure that all XPS and X-ray absorption spectroscopy (XAS) spectroscopic signatures for carbon-nitrogen bond formation are a result of new amine moieties. $\mathrm{ND}-\mathrm{NH}_{3}$ inner-shell chemistry (covalent bonds directly with the diamond lattice) was verified via laboratory and synchrotron-based surface sensitive spectroscopies, as we show with the following evidence. DRIFTS spectra showed that the $(\mathrm{C}-\mathrm{Br})_{v}$ stretching mode at $750 \mathrm{~cm}^{-1}$ was completely removed, and new peaks related to amine functionalization appeared at $1025 \mathrm{~cm}^{-1}$ and $820 \mathrm{~cm}^{-1}$, corresponding to $(\mathrm{C}-\mathrm{N})_{v}$ and $(\mathrm{N}-\mathrm{H})_{\text {wag }}$ modes, respectively (Figure 1B). An unambiguous conversion from a hydrophobic $\mathrm{ND}-\mathrm{Br}$ surface to a hydrophilic $\mathrm{ND}-\mathrm{NH}_{3}$ surface after amination chemistry was evident through the large increase in both the $(\mathrm{O}-\mathrm{H})_{v}$ and $(\mathrm{O}-\mathrm{H})_{\delta}$ modes of adsorbed water observed at $3000-3500 \mathrm{~cm}^{-1}$ and $1630 \mathrm{~cm}^{-1}$, respectively. When comparing ND$\mathrm{OH}$ versus $\mathrm{ND}-\mathrm{NH}_{3}$, the adsorbed water signal increases, and we conclude that the is hydrophilicity qualitatively increased when amine termination is present at $36-52 \%$ surface coverage (see SOM section 4). The colloidal solutions of ND-NH3 were stored in $18 \mathrm{M} \Omega$ water prior to further analysis, and conjugation to folic acid via $N$-hydroxysulfosuccinimide/1-ethyl-3(3-dimethylaminopropyl)carbodiimide (sulfo-NHS/EDC) coupling is described in the procedures and materials section. Conformation of amide bond formation with $\mathrm{ND}-\mathrm{NH}_{3}$ constructs was a demonstration that surface amines were chemically accessible for biolabeling protocols and surface engineering when fluorescent NDs are used.

Ambiguity in assigning chemical moieties with DRIFTS is common, and XPS allowed for a definitive confirmation of $\mathrm{C}-\mathrm{N}$ bond formation after $\mathrm{NH}_{3} \bullet$ THF treatments. We found that successful amine bond formation was a function of $\mathrm{C}-\mathrm{Br}$ density (catalyzed and uncatalyzed ND$\mathrm{Br}$ ) on the ND surface, as observed in Figure 3B, whereby the N1s photoemission spectra show enhanced $\mathrm{C}-\mathrm{N}$ resonance at $400.3 \mathrm{eV}$ and a minor $\mathrm{C}=\mathrm{N}$ feature at $402.6 \mathrm{eV}$, consistent with amination of diamond films with $\mathrm{NH}_{3}$ plasma and $\mathrm{CN}$ thin films. ${ }^{47,60}$ The $\mathrm{C} 1$ s photoemission peaks after amination chemistry also show a deconvolved $\mathrm{C}-\mathrm{N}$ resonance at $286.0 \mathrm{eV}, \mathrm{C}-\mathrm{C}$ resonance at $284.8 \mathrm{eV}$ and contributions from $\mathrm{C}-\mathrm{O}$ and $\mathrm{C}=\mathrm{O}$ at $286.5 \mathrm{eV}$ and $288.0 \mathrm{eV}$, respectively. Based on the XPS atomic \% results, we conclude that the conversion of $\mathrm{ND}-\mathrm{Br} \rightarrow \mathrm{ND}-\mathrm{NH}_{2}$ is unity, with a typical survey scan showing $\mathrm{C} 1 \mathrm{~s}, \mathrm{O} 1 \mathrm{~s}$ and $\mathrm{N} 1 \mathrm{~s}$ percentages of $69.4 \%, 22.8 \%$ and $7.8 \%$, respectively. No Br3d was detected at the atomic concentrations sensitivity levels of the XPS of $0.1 \%$. Amongst the probed $\mathrm{ND}-\mathrm{NH}_{3}$ samples, we estimate that $36-52 \%$ of surface carbon atoms were aminated, which translates to $6.5-9.5$ amines $/ \mathrm{nm}^{2}$ (see SOM section 4). The disparity in the maximum Br3d:N1s (2.5\%:7.8\%) signal is due to instantaneous debromination as a function of time after synthesis and under ultrahigh vacuum conditions. No Br3d photoelectrons were detected in either survey scans or high-resolution scans after the amination and purification steps. The rate of $\mathrm{C}-\mathrm{N}$ bond formation was proportional to the concentration of $\mathrm{C}-\mathrm{Br}$ bonds on the surface, and we conclude that catalyst-free amine bond formation is a consequence of the dissociation of alkyl bromides and the reactive intermediate that was observed using DRIFTS (section 2 in SI). 
Soft X-ray spectroscopy of ND-OH, ND-Br and ND-NH3. XAS measurements of NDs are essential in this work because they provide simultaneous conformation of the presence of diamond (core-hole exciton and 2nd absolute bandgap) while examining the surface termination of nitrogen or oxygen moieties independently (Figure 3). XAS is an element-specific spectroscopy technique that provides information on the electronic structure of molecules and solids, including the chemical state, bond order, bond length and orientation of adsorbates. ${ }^{61}$ In the soft X-ray regime, when collecting in total electron yield (TEY) mode, TEY provides surface and bulk information with a mean probing depth of approximately 5-10 $\mathrm{nm}$. Figure 3A shows the C1s XAS spectra for $\mathrm{ND}-\mathrm{OH}$ and the characteristic features of bulk diamond; we observe little $\mathrm{sp}^{2}$-like carbon near 285 $\mathrm{eV}$, a strong sp ${ }^{3}$ core-hole exciton peak at $289.0 \mathrm{eV}$ and a $2^{\text {nd }}$ absolute bandgap at $302 \mathrm{eV} .^{62,63}$ The $\mathrm{C} 1 \mathrm{~s}$ spectra of ND-OH have weak signals associated with $\pi^{*}{ }_{(\mathrm{C}=\mathrm{C})}$ (approximately $285.3 \mathrm{eV}$ ) due to amorphous carbon and carbonyl $\left(\pi^{*}(\mathrm{C}=\mathrm{O})\right.$ transitions, covering $\left.286.5-288 \mathrm{eV}\right)$ prior to the large core-hole exciton peak at $289.0 \mathrm{eV}$. After bromination, ND-Br shows new features in the 286$288.5 \mathrm{eV}$ region with strong resonances at $287.2 \mathrm{eV}$ and $288.4 \mathrm{eV}$ and is assigned to the $\sigma^{*}{ }_{(\mathrm{C}-\mathrm{Br})}$ electronic states due to unoccupied $\mathrm{Br}$ p-orbitals bound to the diamond surface. ${ }^{51}$ The amplitude of the carbon-bromine resonances is increased for a surface species in TEY mode and is due to the larger photon absorption cross section of the $1 \mathrm{~s} \rightarrow \mathrm{p}$ transitions of brominated diamond. O1s data for ND-OH are dominated by the $\sigma^{*}{ }_{(\mathrm{C}-\mathrm{O})}$ at $540 \mathrm{eV}$ due to alcohols and small $\pi^{*}{ }_{(\mathrm{C}=\mathrm{O})}$ transitions due to carbonyls at $534 \mathrm{eV}$. After bromination, minor O1s features arise at $532 \mathrm{eV}$ and $542-550$ $\mathrm{eV}$ due to $\pi^{*}{ }_{(\mathrm{Br}=\mathrm{O})}$ and $\sigma^{*}(\mathrm{O}-\mathrm{Br})$ and resonances, respectively. Due to the atomically dense diamond surface, we consider that both alkyl bromides and different carbon-oxygen-bromine bonding environments may exist simultaneously.

N1s XAS presents key signatures of $\mathrm{C}=\mathrm{N}, \mathrm{C}-\mathrm{N}$ and $\mathrm{N}-\mathrm{H}$ bond formation after catalyst-free amination chemistry at room temperature. Challenges exist in performing N1s XAS on diamond due to the large $\mathrm{C} 1 \mathrm{~s}$ background at high energy $(380-420 \mathrm{eV})$ that the N1s near-edge features are convolved with. First, we assign the weak low energy resonance at $398.5 \mathrm{eV}$ to the $\pi^{*}(\mathrm{~N}-\mathrm{C}=\mathrm{O})$ of a carboxyamide and reinforce this assignment by probing a control sample. An amide was prepared with a silica-coated ND functionalized with amines (3-aminopropyl-triemethoxysilane, i.e., APTES), conjugated to folic acid via sulfo-NHS/EDC coupling and produced a strong $\pi^{*}(\mathrm{~N}-\mathrm{C}=\mathrm{O})$ peak at $398.2 \mathrm{eV}$ (Figure 4B and SOM section 5). The feature at $398.5 \mathrm{eV}$ is assigned to a carboxyamide on the ND surface and has enhanced $\pi$-character due to the nitrogen lone pair delocalization with the carbonyl. ${ }^{64}$ Low-energy N1s peaks $(398-400 \mathrm{eV})$ are typically assigned to $1 \mathrm{~s} \rightarrow \pi^{*}$ transitions, and the presence of $\mathrm{C}=\mathrm{N}$ features has been observed in 6-ring heterocycles such as cytosine and pyrazinecarboxamide. ${ }^{65}$ Our findings are consistent with Graf et al., who studied APTES on silica and assigned N1s signals at $\sim 388 \mathrm{eV}$ to $\pi^{*}{ }_{(\mathrm{C}=\mathrm{N})}$ due to radiation damageinduced deprotonation and we observed similar features (section 5 in SI). The feature at $400.5 \mathrm{eV}$ is assigned to the $\sigma^{*}(\mathrm{~N}-\mathrm{H})$ of a primary or secondary amine and is consistent across amination with $\mathrm{NH}_{3} \bullet$ THF, hydrazine- and folic acid-conjugated samples. ${ }^{64,66}$ The higher energy features at 404.8 $\mathrm{eV}$ and $407.6 \mathrm{eV}$ are assigned to the $\sigma^{*}{ }_{(\mathrm{C}-\mathrm{N})}$ bonding environment. $\mathrm{ND}-\mathrm{NH}_{3} 1 \mathrm{~s} \rightarrow \sigma^{*}$ transitions are due to a primary amine $\mathrm{C}-\mathrm{N}$ and possibly a $\mathrm{C}-\mathrm{N}-\mathrm{C}$ bridging configuration similar to a secondary amine. When $\mathrm{ND}^{-\mathrm{NH}_{3}}$ samples are conjugated to folic acid and amide bond formation occurs, several key features change as the nitrogen lone-pair electrons contribute to the delocalized bonding environment. The $\pi^{*}{ }_{(\mathrm{C}=\mathrm{N})}$ resonance at $398.5 \mathrm{eV}$ increases in intensity, $\sigma^{*}{ }_{(\mathrm{N}-\mathrm{H})}$ remains at 
$400.5 \mathrm{eV}, \sigma^{*}(\mathrm{C}-\mathrm{N})$ peak becomes a broadened peak at $407 \mathrm{eV}$, and double peaks are no longer present. These assignments are reinforced by the control experiments with amine-functionalized silica bound to folic acid, and the conversion is evident (section 5 in SI). Recent N1s XAS studies of gas phase and aqueous $\mathrm{NH}_{3}$ and $\mathrm{NH}_{4}{ }^{+}$show similar resonances to our study and report that distinct lower energy features at $401-402 \mathrm{eV}$ are assigned to $\mathrm{NH}_{3}$ while $\mathrm{NH}_{4}{ }^{+}$features are not observed until $405 \mathrm{eV}$ and above. ${ }^{67,68} \mathrm{We}$ highlight these new reports because the N1s spectra reported in Figure 3B may contain contributions of $\mathrm{ND}-\mathrm{NH}_{2}$ and $\mathrm{ND}-\mathrm{NH}_{3}$ due to a tightly bound water layer and hydrogen bonding that may exist on the ND surface. $\mathrm{ND}-\mathrm{NH}_{3}$ samples were not desiccated at high temperature in vacuo prior to deposition in the same fashion that ND-OH samples were prepared.

Transition Edge Sensor, RIXS, PFY-XAS and XES. The transition edge sensor (TES) detector housed at beamline 10-1 at the Stanford Synchrotron Radiation Lightsource (SSRL) provides background-free X-ray emission data and electronic structure information of the valence (occupied) and conduction (unoccupied) density of states (DOS) of both the ND and surface moieties. ${ }^{69,70}$ Resonant inelastic X-ray scattering or RIXS maps provides the complete DOS with extraction of X-ray emission spectroscopy (XES) data and partial fluorescence yield X-ray absorption spectroscopy (PFY-XAS). XES and PFY-XAS spectra is produced with an integration window with a static emission or excitation energy as highlighted with the dashed white box in Figure 4B. Figure 4A shows $\mathrm{C}, \mathrm{N}$ and $\mathrm{O} \mathrm{K} \alpha$ emission data after amination chemistry performed at $-77^{\circ} \mathrm{C}, 25^{\circ} \mathrm{C}$ and $600^{\circ} \mathrm{C}$ with condensed $\mathrm{NH}_{3}, \mathrm{NH}_{3} \bullet \mathrm{THF}$ and gaseous $\mathrm{NH}_{3}$, respectively. $\mathrm{C} \mathrm{K \alpha}$ $\mathrm{X}$-ray emission was consistent with past studies of diamond, with bandgap emission beginning at $\sim 284 \mathrm{eV}$ and extending to $250 \mathrm{eV} .^{71}$ The $\mathrm{C} \mathrm{K \alpha}$ emission features above the bandgap (289-312 eV) are different for each ND-NH 2 construct and are potentially due to vibronic coupling to the diamond lattice, surface moieties or Rayleigh scattering. ${ }^{71}$ Importantly, the $\mathrm{N} \mathrm{K \alpha}$ emission data are unique in intensity for each of the chemistries used, extend from 365-440 eV and include both X-ray emission features and Rayleigh scattering. Because XAS/XES data of aminated diamond are scarce, we compare our spectra with model systems of ammonia and N-doped graphene. ${ }^{72,73}$ Our standard $\mathrm{NH}_{3} \bullet \mathrm{THF}$ chemistry of ND-Br constructs yielded 3 distinct regions of emission from 380-402 eV (region A), 408-420 eV (region B) and 420-440 eV (region C). The last two regions show step-like emission and are due to Rayleigh scattering and participator emission, respectively. ${ }^{74}$ Chemical treatment of $\mathrm{ND}-\mathrm{Br}$ with $\mathrm{NH}_{3} \bullet \mathrm{THF}$ at $25^{\circ} \mathrm{C}$ yields amination rates similar to those of $\mathrm{NH}_{3}$ gas at $600^{\circ} \mathrm{C}$, yet the mechanism is expected to be different due to temperaturedependent debromination and surface reconstruction. Nucleophilic addition of $\mathrm{NH}_{3}$ to the tertiary carbocation on the diamond surface at $25^{\circ} \mathrm{C}$ should proceed as depicted in SOM7 with production of an $\mathrm{HBr}$ side product. $\mathrm{NH}_{3}$ gas chemistry at $600^{\circ} \mathrm{C}$ should proceed through thermal debromination at temperatures above $90^{\circ} \mathrm{C}$, desorption of alcohol groups above $500^{\circ} \mathrm{C}$ and Pandey reconstruction of the diamond surface. ${ }^{75}$

We model our XES spectra focusing on the dominant $\mathrm{C}-\mathrm{N}$ and $\mathrm{N}-\mathrm{H}$ occupied density of states and compare the spectra to ammonia and glycine. $\mathrm{NH}_{3} \bullet$ THF treatment yielded a dominant spectator $\mathrm{N} \mathrm{K \alpha}$ peak at $398.3 \mathrm{eV}$, which is assigned to the lone pair electrons on nitrogen or $\mathrm{C}-\mathrm{N}$ bonds and is supported by similar XES features in glycine and DFT calculations of the highest occupied molecular orbital (HOMO) isodensity surfaces. ${ }^{74}$ The $402.5 \mathrm{eV}$ peak is assigned to the $\mathrm{N}-\mathrm{H}$ HOMO orbitals and is very close to a resonant excitation of the $\sigma^{*}(\mathrm{~N}-\mathrm{H})$ transition. The lower energy tail from $380-393 \mathrm{eV}$ is assigned to a mixture of delocalized HOMO states described 
as HOMO-8/9/10 in reference 74. Weinhardt et al. used the StoBe-DeMon package to calculate the transition probabilities based on the ground state Kohn-Sham eigenstates, which accurately calculated the XES spectra of glycine, diglycine and triglycine. Our gas-phase amination chemistry using $\mathrm{NH}_{3} / \mathrm{N}_{2}$ mixtures at $600^{\circ} \mathrm{C}$ produced similar features at $398.3 \mathrm{eV}$ (lone pair electrons amines/C-N) and $402.5 \mathrm{eV}(\mathrm{N}-\mathrm{H})$ with reduced intensity in comparison to that for the $\mathrm{NH}_{3} \bullet \mathrm{THF}$ treatments. A new feature arose at $393.7 \mathrm{eV}$, which we assign to HOMOs of imides $(\mathrm{C}=\mathrm{N})$, consistent with increased $\pi^{*}{ }_{(\mathrm{C}=\mathrm{N})} \mathrm{XAS}$ transitions at $399.5 \mathrm{eV}$ (data not shown). At temperatures above $90^{\circ} \mathrm{C}$ and $500^{\circ} \mathrm{C}$ alkyl bromides and alcohols will desorb and produce $\mathrm{sp}^{2}$-like Pandey chains due to uncoordinated surface sites, and nitrogen insertion is likely to occur. ${ }^{75}$ Gas phase $\mathrm{NH}_{3}$ chemistry at high temperatures is more complex with competing kinetics of thermal desorption, surface reconstruction and new amine/imide bond formation. Amination chemistry at $-77^{\circ} \mathrm{C}$ with liquid ammonia only showed $\mathrm{N} \mathrm{K \alpha}$ features representative of spectator emission, with an asymmetric peak from $380-407 \mathrm{eV}$. The lower kinetic rate of amination and shorter reaction time of 30 minutes resulted in less $\mathrm{C}-\mathrm{N}$ bond formation but did highlight that catalyst-free bond formation still occurred at $-77^{\circ} \mathrm{C}$ (section 7 in SI for RIXS maps).

Propargyl amine reacted with ND-Br. In a demonstration of an uncatalyzed Sonogashira-type coupling reaction, ${ }^{76} \mathrm{ND}-\mathrm{Br}$ was reacted at $25^{\circ} \mathrm{C}$ with propargyl amine (PA), an alkyne, and produced an 11-fold increase in the nitrogen signal in comparison to that of other $\mathrm{ND}-\mathrm{NH}_{3}$ constructs (Figure 4B/C)). The original intent of the PA reaction was to form a new $\mathrm{C}-\mathrm{N}$ surface bond with an outward facing alkyne for click chemistry, yet the reaction did not proceed in the fashion envisioned. A RIXS map details both the occupied and unoccupied electronic structures of the PA-reacted ND samples (Figure 4B). The RIXS map was generated by scanning the X-ray monochromator (excitation energy on the y-axis) and recording the emitted X-rays using the TES detector. The linear feature marked " $R$ " is the Rayleigh scattering of the incident X-rays and is a common feature in RIXS. The RIXS map details a high reactivity level between ND-Br and PA without a metal-based catalyst and should be compared to RIXS maps in section 7 of the SI. Our findings are similar to the uncatalyzed reaction of a brominated precursor and an alkyne by Liu and Li using UV irradiation, which proceeded through a carbocation intermediate. ${ }^{77}$ PFY-XAS reveals this increase in nitrogen content of the $\mathrm{ND}^{-\mathrm{NH}_{3}}$ samples compared to other amination routes (Figure 4C). The PFY-XAS data are produced by integrating the emission intensity as a function of excitation photon energy, are complimentary to traditional XAS and eliminate the high energy background signal of carbon. PFY-XAS peaks at $398.3 \mathrm{eV}$, a shoulder at $401.0 \mathrm{eV}$ and a broad resonance at $406.2 \mathrm{eV}$ are assigned to the $\pi^{*}(\mathrm{C}=\mathrm{N}), \sigma^{*}(\mathrm{~N}-\mathrm{H})$ and $\sigma^{*}{ }_{(\mathrm{C}-\mathrm{N})}$ resonances, respectively. The sharp and intense $\pi^{*}(\mathrm{C}=\mathrm{N})$ feature is evidence that PA polymerized on the ND surface, as explained below.

$\mathrm{N} \mathrm{K} \alpha$ emissions from PA-treated samples have much higher count rates than single carbonnitrogen bonds on the ND surface with $\mathrm{NH}_{3} \bullet \mathrm{THF}$ or $\mathrm{NH}_{3}$ (condensed or gas) chemistry and are evidence of polymerization (section 7 in SI). Comparison of the $\mathrm{N} \mathrm{K \alpha}$ resonant X-ray emission (RXES-blue trace) and nonresonant X-ray emission (NRXES-purple trace) of ND-PA differ in the intense emission at $396.8 \mathrm{eV}$ for the RXES overlapping with the Rayleigh scattering line (marked R) and the lower energy peak positions from 391-392 eV. RXES data were produced by integrating emission counts from 397-400 eV excitation energies (white box in Figure 4B), while NRXES data were obtained by integrating from $410-440 \mathrm{eV}$. The RXES and NRXES peaks are redshifted $1.5 \mathrm{eV}$ and $6.3 \mathrm{eV}$ from the $\mathrm{C}=\mathrm{N}$ resonance at $398.3 \mathrm{eV}$, respectively. The RXES peak that overlaps 
with the Rayleigh line is due to either vibronic coupling or a large overlap between the electron wave function and core hole produced by the exciton, leading to higher emission rates, as observed previously with $\mathrm{NH}_{3}$ and $\mathrm{ND}_{3}{ }^{72,78}$ The vibrational fine structure of the propargyl amine sample was not observed in this study as was observed with $\mathrm{NH}_{3}$. The integrated XES signals (black traces) of $\mathrm{NH}_{3} \bullet \mathrm{THF}, \mathrm{NH}_{3}$ gas at $300^{\circ} \mathrm{C}$ and folic acid-conjugated $\mathrm{NDs}$ are included for comparison. These results are consistent with reactions and polymerizations of aminoalkynes with transition metal catalysts and yield imines and enamines. ${ }^{79}$ Because there is a minor $\pi^{*}(\mathrm{C}=\mathrm{C})$ resonance observed in the PA reaction, we conclude that a polyimine, not an enamine, is the dominant reaction product.

Importantly, the C1s XAS of PA treated samples does not show the core-hole exciton and 2nd bandgap of diamond and is due to a shell of polyimine formed on the ND core via polymerization (section 6 in SI). The suppression of the core-hole exciton in conjunction with the intense nitrogen signal, clear $\pi^{*}{ }_{(\mathrm{C}=\mathrm{N})}$ PYF-XAS signatures caused by imines and $\sigma^{*}{ }_{(\mathrm{C}-\mathrm{N})} \mathrm{N} 1 \mathrm{~s}$ PFYXAS resonance reinforces that multiple layers of reacted PA reside on the ND surface. ${ }^{80}$ We propose two possible mechanisms in which the alkyne or amine reacts with the carbocation after debromination and continues to polymerize in the presence of $\mathrm{HBr}$ (SOM11 in SI). A control reaction of ND-Br with $N$-Boc PA yielded low amination rates, and the presence of the diamond electronic structure was observed (data not shown), showing that suppression of the polymerization reaction had occurred. This Sonogashira-like reaction has not been reported on any ND surface and highlights the level of reactivity of ND-Br under mild conditions and in the absence of a metal cocatalyst. Future studies can control the growth of the PA shell by stopping the reactions at various time intervals and characterizing the ND constructs.

\section{Conclusion}

In summary, we realized the first bromination and subsequent amination of HPHT NDs, provided detailed observations of the diamond-bromine bond and realized subsequent carbonnitrogen bond formation at $25^{\circ} \mathrm{C}$ without the use of catalysts. The formation of alkyl bromides was found to be very labile and sensitive to water and we observed evidence of an intracrystallite Williamson ether-like surface side product. The bromination rates were found to be $36-52 \%$ of the available surface carbon atoms based on XPS analysis and were near the predicted value of 50\% surface coverage based on DFT. The bromination yields were found indirectly by analyzing the atomic \% concentrations of the final $\mathrm{ND}-\mathrm{NH}_{3}$ constructs and was necessary due to the decomposition of ND-Br as a function of time. The lability of the carbon-bromine bond on diamond has been confirmed experimentally here, and this bond is highly unstable compared to that in brominated small molecule analogs. Uncatalyzed carbon-nitrogen bond formation is understood by the good leaving group properties of $\mathrm{ND}-\mathrm{Br}$, readily forming a reactive intermediate that subsequently leads to covalent amine termination. As a proof of concept relevant for biolabeling with NV diamond, we conjugated folic acid to $\mathrm{ND}-\mathrm{NH}_{3}$ constructs and found evidence of amide bond formation. The use of synchrotron spectroscopy and the TES detector allowed detailed examination of the occupied and unoccupied electronic states of the ND surface termination, and we found that propargylamine reacted with ND-Br to yield polyimines in an uncatalyzed Sonogashira-type reaction. This work is impactful for researchers who wish to explore heteroatom chemistry on diamond and other ultrahard, ultra-dense materials (e.g., silicon carbide or boron carbide). We envision researchers using HPHT NDs for quantum sensing or as a source 
of free electrons will find this new methodology for activating diamond surfaces can broadly applied as new nucleophiles are explored. 
Figures
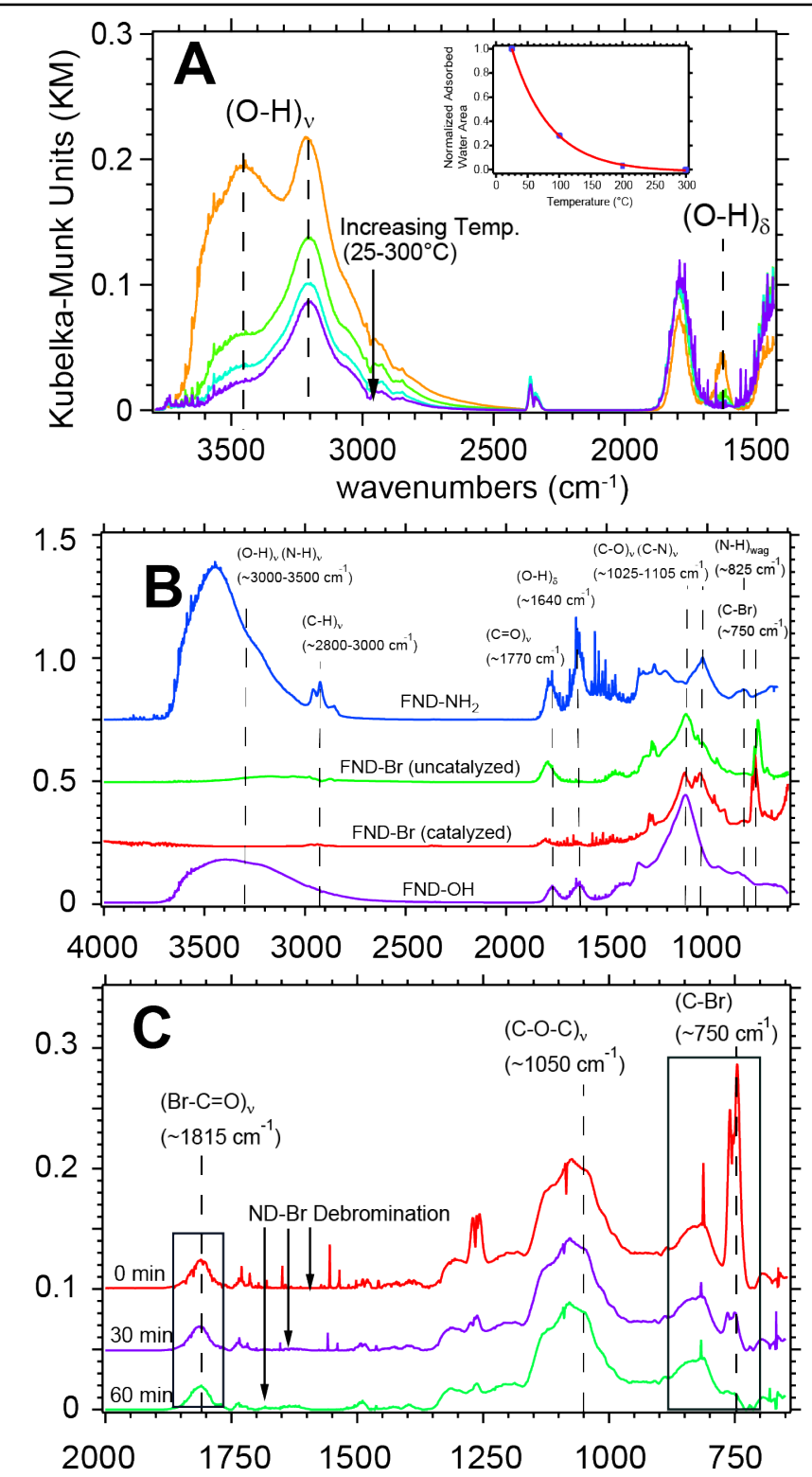

Figure 1. DRIFTS data showing the transition from $\mathrm{ND}-\mathrm{OH} \rightarrow \mathrm{ND}-\mathrm{Br} \rightarrow \mathrm{ND}-\mathrm{NH}_{2}$ under open-air and inert atmosphere conditions. TPD-DRIFTS data from $25-300^{\circ} \mathrm{C}$ confirm the contribution of $(\mathrm{O}-\mathrm{H})_{v}$ stretching modes due to both adsorbed water and the hydroxyl-terminated diamond (panel A). The $(\mathrm{O}-\mathrm{H}) \mathrm{v}$ band from $3000-3500 \mathrm{~cm}^{-1}$ decreases proportionally to the elimination of $(\mathrm{O}-\mathrm{H})_{\delta}$ at $1630 \mathrm{~cm}^{-1}$. The inset shows the integrated $(\mathrm{O}-\mathrm{H})_{\delta}$ signal in KubelkaMunk units as a function of temperature. DRIFTS spectra reveal a strong $(\mathrm{C}-\mathrm{Br})_{v}$ signal at $750 \mathrm{~cm}^{-1}$ that confirms alkyl bromide formation on the ND surface after addition of $\mathrm{SOBr}_{2}$ for 24 hours with and without the presence of pyridine (panel B). After amination chemistry, $\mathrm{ND}-\mathrm{NH}_{2}$ becomes highly hydrophilic; the $(\mathrm{C}-\mathrm{N})_{v}$ mode becomes prominent at $1025 \mathrm{~cm}^{-1}$, a small $(\mathrm{N}-\mathrm{H})_{\text {wag }}$ signal at $825 \mathrm{~cm}^{-1}$ is observed and the $(\mathrm{C}-\mathrm{Br})_{v}$ peak is absent (Panel B). In situ reactivity of the alkyl-bromides under open-air conditions was tracked by opening two small valves on an inert atmosphere DRIFTS chamber and monitoring the decrease in the $(\mathrm{C}-\mathrm{Br})_{v}$ intensity at $750 \mathrm{~cm}^{-1}$ with pseudo-first-order kinetics (panel C). Note: During the debromination process, the $(\mathrm{C}-\mathrm{O}-\mathrm{C})_{v}$ signal at $1075 \mathrm{~cm}^{-1}$ remained unchanged and did not convert readily back to the representative alcohol peak position of $1100 \mathrm{~cm}^{-1}$. 


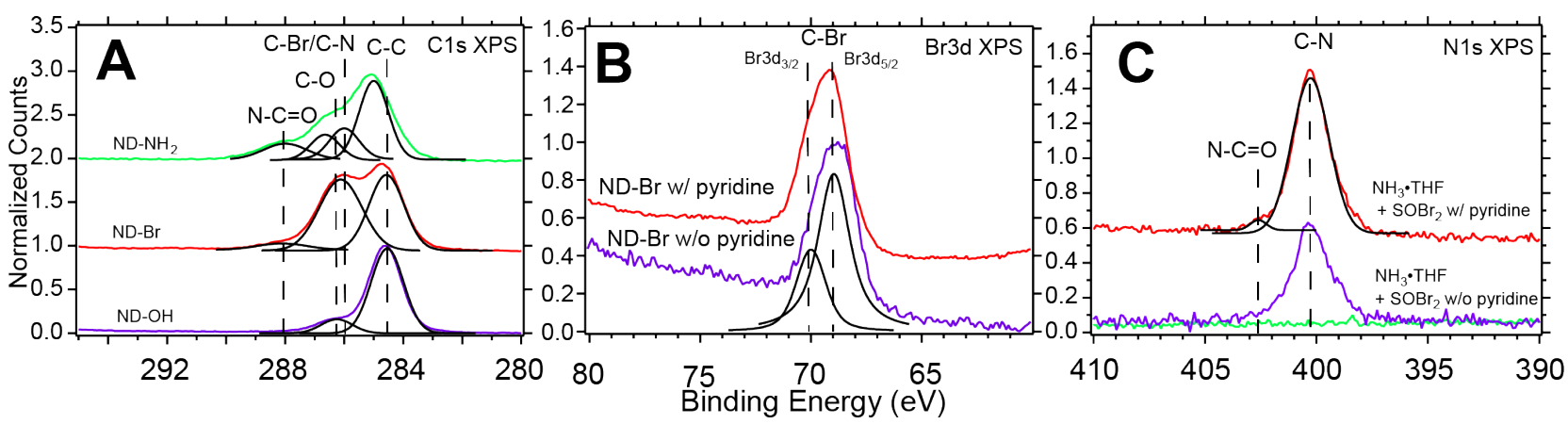

Figure 2. Br3d, N1s and C1s XPS spectra confirming the conversion of alcohol-rich diamond surfaces (ND-OH) to alkyl-bromide terminated $\mathrm{ND}-\mathrm{Br}$ and amine terminated $\mathrm{ND}-\mathrm{NH}_{2}$. ND-Br constructs show strong Br3d XPS peaks at $\sim 69$ and $70 \mathrm{eV}$, which are consistent with $\mathrm{C}-\mathrm{Br}$ bond formation, and $\mathrm{Br} 3 \mathrm{~d}_{3 / 2}$ and $\mathrm{Br}_{3} \mathrm{~d}_{5 / 2}$ spin-orbit contributions are Gaussian fitted with $\Delta \mathrm{E}=1.04 \mathrm{eV}$. The rising edge in the $\mathrm{Br} 3 \mathrm{~d}$ XPS spectrum is due to the Au substrate on which the ND-Br is deposited (A). The $400.3 \mathrm{eV}$ peak in the $\mathrm{N} 1 \mathrm{~s}$ spectrum is assigned to formed $\mathrm{C}-\mathrm{N}$ bonds, while a minor peak at 402.7 $\mathrm{eV}$ is assigned to an amide bond (B). The $\mathrm{C} 1 \mathrm{~s}$ spectrum shows the evolution of $\mathrm{ND}-\mathrm{OH} \rightarrow \mathrm{ND}-\mathrm{Br} \rightarrow \mathrm{ND}-\mathrm{NH}_{2}$ with contributions from $\mathrm{C}-\mathrm{O}, \mathrm{C}-\mathrm{Br}$ and $\mathrm{C}-\mathrm{N}$ bonds at each stage, respectively. 

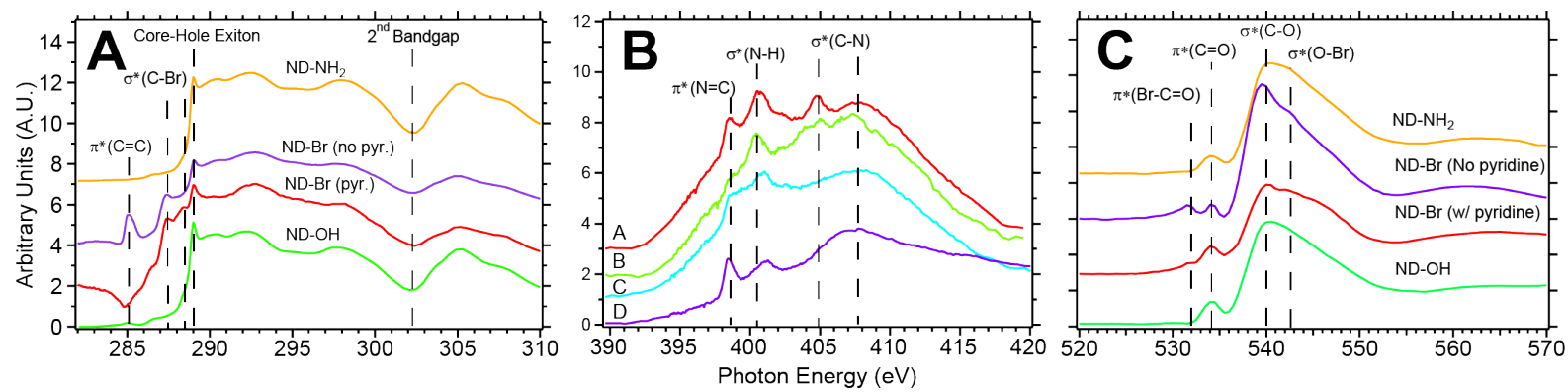

Figure 3. XAS spectra of ND-OH, ND-Br and ND-NH 2 probing the excited and ground state electronic structure of the nanodiamond constructs. $\mathrm{C} 1 \mathrm{~s}$ and $\mathrm{O} 1 \mathrm{~s}$ XAS data show the emergence of $\sigma^{*}(\mathrm{C}-\mathrm{Br})$ and $\pi^{*}(\mathrm{Br}-\mathrm{C}=\mathrm{O})$ transitions after bromination chemistry and its elimination after amination chemistry (A and B). N1s XAS spectra of ND-NH$H_{2}$ constructs produced by reaction with $\mathrm{NH}_{3} \bullet \mathrm{THF}$ (plots A/B), hydrazine (C) and amide bond formation to folic acid via sulfo-NHS/EDC. $\pi^{*}(\mathrm{C}=\mathrm{N}), \sigma^{*}(\mathrm{~N}-\mathrm{H})$ and $\sigma^{*}(\mathrm{C}-\mathrm{N})$ transitions are observed at $398.5 \mathrm{eV}, 400.5$ $\mathrm{eV}$ and $405 / 407.8 \mathrm{eV}$, respectively. 


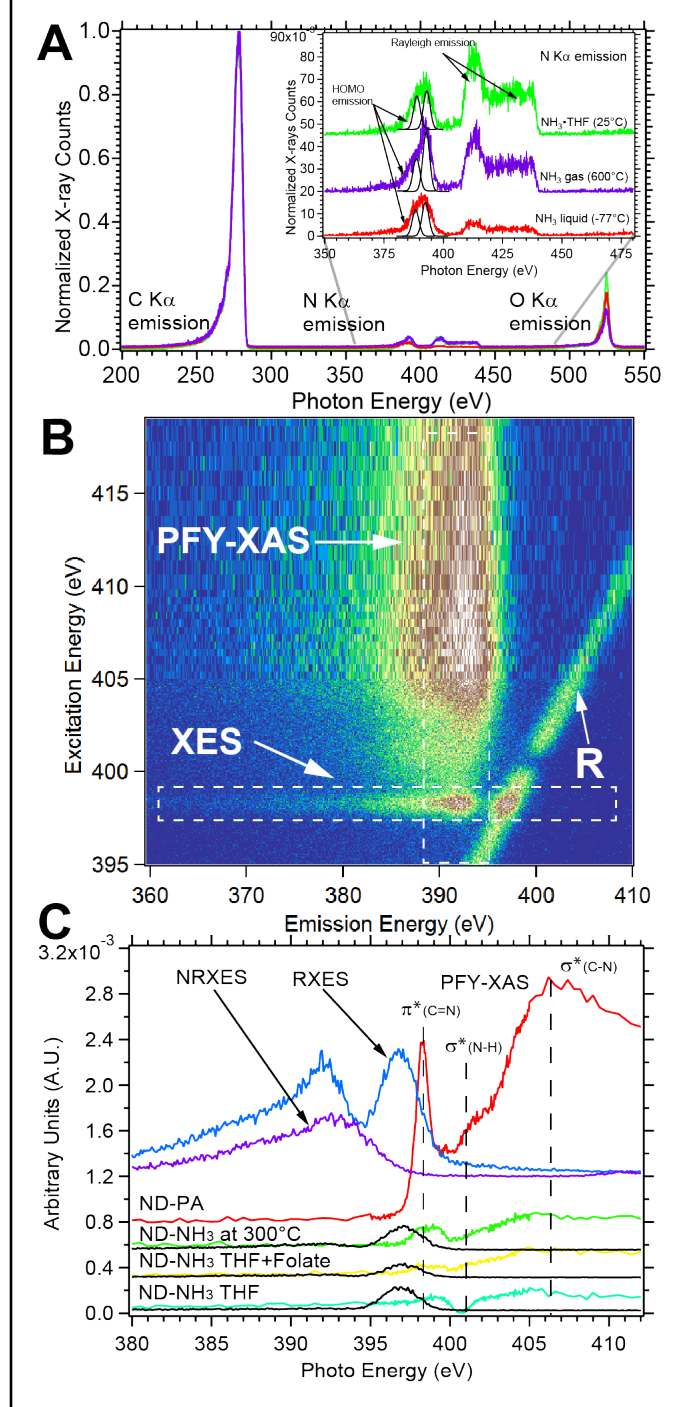

Figure 4. XES, RIXS and PFY-XAS spectra of ND-OH, $\mathrm{ND}-\mathrm{Br}$ and $\mathrm{ND}-\mathrm{NH}_{2}$ probing the excited and ground state electronic structure of the nanodiamond constructs, collected with the TES detector. The N1s RIXS map of propargylamine-treated $\mathrm{ND}-\mathrm{Br}$ samples shows an $11 \mathrm{X}$ fold increase in the amine signal (B). PFY-XAS and XES plots were extracted with integration, as illustrated by the white dashed boxes. The PFY-XAS spectrum shows a $\pi^{*}(\mathrm{C}=\mathrm{N})$ transition at $398.1 \mathrm{eV}$ and a broad $\sigma^{*}(\mathrm{C}-\mathrm{N})$ transition at $406.5 \mathrm{eV}$, while the XES spectrum shows peak emission at $392.5 \mathrm{eV}$ and decreasing spectator emission to $380 \mathrm{eV}$ (B). Other aminated samples with $\mathrm{NH}_{3} \bullet \mathrm{THF}, \mathrm{NH}_{3}$ gas at $300^{\circ} \mathrm{C}$ and after folic acid conjugation are shown for comparison. Off-resonance XES signals (integration from $410-440 \mathrm{eV}$ excitation energy) show distinct above- and below-bandgap emission for amination at $-77^{\circ} \mathrm{C}, 25^{\circ} \mathrm{C}$ and $600^{\circ} \mathrm{C}(\mathrm{A})$. 


\section{Acknowledgments.}

Abraham Wolcott would like to acknowledge financial support through the National Institutes of Health NIGMS office (1SC3GM125574-01) and Army Research Office (W911NF1810453 and W911NF17S000205) through the Department of Defense. Petr Cigler would like to acknowledge financial support through the Czech Science Foundation Project No. 18-17071 S (to P.C.), MSM Project No. 8C18004 (NanoSpin) (to P.C., H.R.), European Regional Development Fund; OP RDE; Projects: Chem-BioDrug (No. CZ.02.1.01/0.0/0.0/16_019/0000729) (to P.C., H.R.) and CARAT (No. CZ.02.1.01/0.0/0.0/16_026/0008382) (to P.C., H.R.). Work at the Molecular Foundry was supported by the Office of Science, Office of Basic Energy Sciences, of the U.S. Department of Energy under Contract No. DE-AC02-05CH11231. The TES spectrometer was developed with funding from the Department of Energy, Laboratory Directed Research and Development program under Contract No. DE-AC02-76SF00515. This work was supported by the U.S. Department of Energy Office of Basic Energy Sciences Proposal No. 100487. The use of the Stanford Synchrotron Radiation Lightsource, SLAC National Accelerator Laboratory, is supported by the U.S. Department of Energy, Office of Science, Office of Basic Energy Sciences under Contract No. DE-AC02-76SF00515. Sami Sainio acknowledges funding from the Walter Ahlström Foundation. S.S. also received funding from the European Union's Horizon 2020 Research and Innovation Programme under the Marie Skłodowska-Curie grant agreement No 841621. Perla Jasmine Sandoval, Jocelyn Valenzuela and Grace Jeanpierre would like to acknowledge support through the MARC and RISE program at SJSU (5T34GM008253-33 and 5R25GM071381-13).

Author Contributions. CM, JLR, CXS, TCC, JV, GJ, HM, PT, PJS and TS generated samples, collected data and analyzed data. SJL, CJT, SS and DN maintained the SSRL beamlines, facilitated beamline runs, assisted in data interpretation and contributed to writing of the manuscript. VA trained users and facilitated use of instrumentation at The Molecular Foundry. JV, HR and VV generated samples. WBD, GCO, DSS, JNU and KI created, installed and maintained the transition edge sensor at Stanford Synchrotron Radiation Lightsource. PC and AW conceived of the experimental structure, guided research, provided data analysis and wrote the manuscript.

Financial Conflicts: There are no competing financial interests among the authors. 


\section{References}

1. Saikia, I.; Borah, A. J.; Phukan, P., Use of Bromine and Bromo-Organic Compounds in Organic Synthesis. Chemical Reviews 2016, 116 (12), 6837-7042.

2. Ullmann, F.; Bielecki, J., Ueber Synthesen in der Biphenylreihe. Berichte der deutschen chemischen Gesellschaft 1901, 34 (2), 2174-2185.

3. Chinchilla, R.; Nájera, C., Recent advances in Sonogashira reactions. Chemical Society Reviews 2011, 40 (10), 5084-5121.

4. Lafferentz, L.; Eberhardt, V.; Dri, C.; Africh, C.; Comelli, G.; Esch, F.; Hecht, S.; Grill, L., Controlling on-surface polymerization by hierarchical and substrate-directed growth. Nature Chemistry 2012, 4 (3), 215-220.

5. Grill, L.; Dyer, M.; Lafferentz, L.; Persson, M.; Peters, M. V.; Hecht, S., Nano-architectures by covalent assembly of molecular building blocks. Nature Nanotechnology 2007, 2 (11), 687-691.

6. Dresselhaus, M. S.; Jorio, A.; Hofmann, M.; Dresselhaus, G.; Saito, R., Perspectives on Carbon Nanotubes and Graphene Raman Spectroscopy. Nano Letters 2010, 10 (3), 751-758.

7. Jankovsky, O.; Simek, P.; Klimova, K.; Sedmidubsky, D.; Matejkova, S.; Pumera, M.; Sofer, Z., Towards graphene bromide: bromination of graphite oxide. Nanoscale 2014, 6 (11), 6065-6074.

8. Bulusheva, L. G.; Okotrub, A. V.; Flahaut, E.; Asanov, I. P.; Gevko, P. N.; Koroteev, V. O.; Fedoseeva, Y. V.; Yaya, A.; Ewels, C. P., Bromination of Double-Walled Carbon Nanotubes. Chemistry of Materials 2012, 24 (14), 2708-2715.

9. Hines, D.; Rümmeli, M. H.; Adebimpe, D.; Akins, D. L., High-yield photolytic generation of brominated single-walled carbon nanotubes and their application for gas sensing. Chemical Communications 2014, 50 (78), 11568-11571.

10. Ikeda, Y.; Saito, T.; Kusakabe, K.; Morooka, S.; Maeda, H.; Taniguchi, Y.; Fujiwara, Y., Halogenation and butylation of diamond surfaces by reactions in organic solvents. Diamond and Related Materials 1998, 7 (6), 830-834.

11. Raymakers, J.; Haenen, K.; Maes, W., Diamond surface functionalization: from gemstone to photoelectrochemical applications. Journal of Materials Chemistry C 2019, 7 (33), 10134-10165.

12. Zhang, B.; Yan, J.; Shang, Y.; Wang, Z., Synthesis of Fluorescent Micro- and Mesoporous Polyaminals for Detection of Toxic Pesticides. Macromolecules 2018, 51 (5), 1769-1776.

13. Field, J., The Properties of Diamond. Academic Press: 1979.

14. Lee, J. Y.; Kang, M. H., First-principles study of the $\mathrm{Cl}$ and $\mathrm{Br}$ adsorbed $\mathrm{Si}(100)$ surfaces. Physical Review B 2004, 69 (11), 113307-1.

15. Bedzyk, M.; Materlik, G., X-RAY STANDING WAVE ANALYSIS FOR BROMINE CHEMISORBED ON GERMANIUM. Surface Science 1985, 152 (APR), 10-16.

16. Develyn, M. P.; Yang, Y. M. L.; Cohen, S. M., ADSORPTION, DESORPTION, AND DECOMPOSITION OF HCL AND HBR ON GE(100) - COMPETITIVE PAIRING AND NEAR-FIRST-ORDER DESORPTION-KINETICS. Journal of Chemical Physics 1994, 101 (3), 2463-2475.

17. Martin, R.; Heydorn, P. C.; Alvaro, M.; Garcia, H., General Strategy for High-Density Covalent Functionalization of Diamond Nanoparticles Using Fenton Chemistry. Chemistry of Materials 2009, 21 (19), 4505-4514.

18. Mamin, H. J.; Kim, M.; Sherwood, M. H.; Rettner, C. T.; Ohno, K.; Awschalom, D. D.; Rugar, D., Nanoscale Nuclear Magnetic Resonance with a Nitrogen-Vacancy Spin Sensor. Science 2013, 339 (6119), 557-560.

19. Staudacher, T.; Raatz, N.; Pezzagna, S.; Meijer, J.; Reinhard, F.; Meriles, C. A.; Wrachtrup, J., Probing molecular dynamics at the nanoscale via an individual paramagnetic centre. Nature Communications 2015, 6, 8527.

20. Karaveli, S.; Gaathon, O.; Wolcott, A.; Sakakibara, R.; Shemesh, O. A.; Peterka, D. S.; Boyden, E. S.; Owen, J. S.; Yuste, R.; Englund, D., Modulation of nitrogen vacancy charge state and fluorescence 
in nanodiamonds using electrochemical potential. Proceedings of the National Academy of Sciences of the United States of America 2016, 113 (15), 3938-3943.

21. de Theije, F. K.; Reedijk, M. F.; Arsic, J.; van Enckevort, W. J. P.; Vlieg, E., Atomic structure of diamond $\{111\}$ surfaces etched in oxygen water vapor. Physical Review B 2001, 64 (8), 085403.

22. Wolcott, A.; Schiros, T.; Trusheim, M. E.; Chen, E. H.; Nordlund, D.; Diaz, R. E.; Gaathon, O.; Englund, D.; Owen, J. S., Surface Structure of Aerobically Oxidized Diamond Nanocrystals. Journal of Physical Chemistry C 2014, 118 (46), 26695-26702.

23. Kono, S.; Kageura, T.; Hayashi, Y.; Ri, S.-G.; Teraji, T.; Takeuchi, D.; Ogura, M.; Kodama, H.; Sawabe, A.; Inaba, M.; Hiraiwa, A.; Kawarada, H., Carbon 1s X-ray photoelectron spectra of realistic samples of hydrogen-terminated and oxygen-terminated CVD diamond (111) and (001). Diamond and Related Materials 2019, 93, 105-130.

24. Wang, X. F.; Ruslinda, A. R.; Ishiyama, Y.; Ishii, Y.; Kawarada, H., Higher coverage of carboxylic acid groups on oxidized single crystal diamond (001). Diamond and Related Materials 2011, 20 (10), 13191324.

25. Loh, K. P.; Xie, X. N.; Yang, S. W.; Zheng, J. C., Oxygen adsorption on (111)-oriented diamond: A study with ultraviolet photoelectron spectroscopy, temperature-programmed desorption, and periodic density functional theory. Journal of Physical Chemistry B 2002, 106 (20), 5230-5240.

26. de Theije, F. K.; van Veenendaal, E.; van Enckevort, W. J. P.; Vlieg, E., Oxidative etching of cleaved synthetic diamond $\{111\}$ surfaces. Surface Science 2001, 492 (1-2), 91-105.

27. Chang, Y. R.; Lee, H. Y.; Chen, K.; Chang, C. C.; Tsai, D. S.; Fu, C. C.; Lim, T. S.; Tzeng, Y. K.; Fang, C. Y.; Han, C. C.; Chang, H. C.; Fann, W., Mass production and dynamic imaging of fluorescent nanodiamonds. Nature Nanotechnology 2008, 3 (5), 284-288.

28. Scholze, A.; Schmidt, W. G.; Bechstedt, F., Structure of the diamond (111) surface: Singledangling-bond versus triple-dangling-bond face. Physical Review B 1996, 53 (20), 13725-13733.

29. Ramasheshan, S., The cleavage properties of diamond. Proc. Indian Acad. Sci. A 1946, 24 (114).

30. Telling, R. H.; Pickard, C. J.; Payne, M. C.; Field, J. E., Theoretical strength and cleavage of diamond. Physical Review Letters 2000, 84 (22), 5160-5163.

31. Rehor, I.; Cigler, P., Precise estimation of HPHT nanodiamond size distribution based on transmission electron microscopy image analysis. Diamond and Related Materials 2014, 46, 21-24.

32. Mochalin, V. N.; Shenderova, O.; Ho, D.; Gogotsi, Y., The properties and applications of nanodiamonds. Nature Nanotechnology 2012, 7 (1), 11-23.

33. Costa, G. C. C.; Shenderova, O.; Mochalin, V.; Gogotsi, Y.; Navrotsky, A., Thermochemistry of nanodiamond terminated by oxygen containing functional groups. Carbon 2014, 80, 544-550.

34. Krueger, A.; Lang, D., Functionality is Key: Recent Progress in the Surface Modification of Nanodiamond. Advanced Functional Materials 2012, 22 (5), 890-906.

35. Osswald, S.; Yushin, G.; Mochalin, V.; Kucheyev, S. O.; Gogotsi, Y., Control of sp(2)/sp(3) carbon ratio and surface chemistry of nanodiamond powders by selective oxidation in air. Journal of the American Chemical Society 2006, 128 (35), 11635-11642.

36. Osswald, S.; Mochalin, V. N.; Havel, M.; Yushin, G.; Gogotsi, Y., Phonon confinement effects in the Raman spectrum of nanodiamond. Physical Review B 2009, 80 (7), 075419.

37. Borodich, F. M.; Korach, C. S.; Keer, L. M., Modeling the Tribochemical Aspects of Friction and Gradual Wear of Diamond-Like Carbon Films. Journal of Applied Mechanics 2005, 74 (1), 23-30.

38. Kruger, A.; Liang, Y. J.; Jarre, G.; Stegk, J., Surface functionalisation of detonation diamond suitable for biological applications. Journal of Materials Chemistry 2006, 16 (24), 2322-2328.

39. Chang, B. M.; Lin, H. H.; Su, L. J.; Lin, W. D.; Lin, R. J.; Tzeng, Y. K.; Lee, R. T.; Lee, Y. C.; Yu, A. L.; Chang, H. C., Highly Fluorescent Nanodiamonds Protein-Functionalized for Cell Labeling and Targeting. Advanced Functional Materials 2013, 23 (46), 5737-5745. 
40. Nguyen, T. T. B.; Chang, H. C.; Wu, V. W. K., Adsorption and hydrolytic activity of lysozyme on diamond nanocrystallites. Diamond and Related Materials 2007, 16 (4-7), 872-876.

41. Bumb, A.; Sarkar, S. K.; Billington, N.; Brechbiel, M. W.; Neuman, K. C., Silica Encapsulation of Fluorescent Nanodiamonds for Colloidal Stability and Facile Surface Functionalization. Journal of the American Chemical Society 2013, 135 (21), 7815-7818.

42. Rehor, I.; Slegerova, J.; Kucka, J.; Proks, V.; Petrakova, V.; Adam, M. P.; Treussart, F.; Turner, S.; Bals, S.; Sacha, P.; Ledvina, M.; Wen, A. M.; Steinmetz, N. F.; Cigler, P., Fluorescent Nanodiamonds Embedded in Biocompatible Translucent Shells. Small 2014, 10 (6), 1106-1115.

43. Rehor, I.; Lee, K. L.; Chen, K.; Hajek, M.; Havlik, J.; Lokajova, J.; Masat, M.; Slegerova, J.; Shukla, S.; Heidari, H.; Bals, S.; Steinmetz, N. F.; Cigler, P., Plasmonic Nanodiamonds: Targeted Core-Shell Type Nanoparticles for Cancer Cell Thermoablation. Advanced Healthcare Materials 2015, 4 (3), 460-468.

44. Vavra, J.; Rehor, I.; Rendler, T.; Jani, M.; Bednar, J.; Baksh, M. M.; Zappe, A.; Wrachtrup, J.; Cigler, P., Supported Lipid Bilayers on Fluorescent Nanodiamonds: A Structurally Defined and Versatile Coating for Bioapplications. Advanced Functional Materials 2018, 28 (45).

45. Stacey, A.; O'Donnell, K. M.; Chou, J. P.; Schenk, A.; Tadich, A.; Dontschuk, N.; Cervenka, J.; Pakes, C.; Gali, A.; Hoffman, A.; Prawer, S., Nitrogen Terminated Diamond. Advanced Materials Interfaces 2015, 2 (10), 1500079.

46. Sotowa, K.-I.; Amamoto, T.; Sobana, A.; Kusakabe, K.; Imato, T., Effect of treatment temperature on the amination of chlorinated diamond. Diamond and Related Materials 2004, 13 (1), 145-150.

47. Zhu, D.; Bandy, J. A.; Li, S.; Hamers, R. J., Amino-terminated diamond surfaces: Photoelectron emission and photocatalytic properties. Surface Science 2016, 650, 295-301.

48. Jirasek, V.; Cech, J.; Kozak, H.; Artemenko, A.; Cernak, M.; Kromka, A., Plasma treatment of detonation and HPHT nanodiamonds in diffuse coplanar surface barrier discharge in $\mathrm{H}-2 / \mathrm{N}-2$ flow. Physica Status Solidi a-Applications and Materials Science 2016, 213 (10), 2680-2686.

49. Simon, N.; Charrier, G.; Goncalves, A. M.; Aureau, D.; Gautier, P.; Ndjeri, M.; Etcheberry, A., Direct amination of diamond surfaces by electroless treatment in liquid ammonia solution. Electrochemistry Communications 2014, 42, 17-20.

50. Zhu, D.; Zhang, L. H.; Ruther, R. E.; Hamers, R. J., Photo-illuminated diamond as a solid-state source of solvated electrons in water for nitrogen reduction. Nature Materials 2013, 12 (9), 836-841.

51. Tiwari, A. K.; Goss, J. P.; Briddon, P. R.; Wright, N. G.; Horsfall, A. B.; Rayson, M. J., Bromine functionalisation of diamond: An ab initio study. Physica Status Solidi a-Applications and Materials Science 2012, 209 (9), 1703-1708.

52. P M. Chu, F. R. G., G C. Rhoderick, Walter J. Lafferty, The NIST Quantitative Infrared Database. Journal of Research of the National Institute of Standards and Technology 1999, 104 (1), 59-81.

53. Ryan, R. G.; Stacey, A.; O’Donnell, K. M.; Ohshima, T.; Johnson, B. C.; Hollenberg, L. C. L.; Mulvaney, P.; Simpson, D. A., Impact of Surface Functionalization on the Quantum Coherence of NitrogenVacancy Centers in Nanodiamonds. ACS Applied Materials \& Interfaces 2018, 10 (15), 13143-13149.

54. Williamson, A., XLV. Theory of ætherification. The London, Edinburgh, and Dublin Philosophical Magazine and Journal of Science 1850, 37 (251), 350-356.

55. Johnstone, R. A. W.; Rose, M. E., RAPID, SIMPLE, AND MILD PROCEDURE FOR ALKYLATION OF PHENOLS, ALCOHOLS, AMIDES AND ACIDS. Tetrahedron 1979, 35 (18), 2169-2173.

56. Smykalla, L.; Shukrynau, P.; Korb, M.; Lang, H.; Hietschold, M., Surface-confined 2D polymerization of a brominated copper-tetraphenylporphyrin on $\mathrm{Au}(111)$. Nanoscale 2015, 7 (9), 42344241.

57. Tiwari, A. K.; Goss, J. P.; Briddon, P. R.; Wright, N. G.; Horsfall, A. B.; Jones, R.; Pinto, H.; Rayson, M. J., Calculated electron affinity and stability of halogen-terminated diamond. Physical Review B 2011, 84 (24), 245305. 
58. Larsson, K.; Lunell, S., Stability of halogen-terminated diamond (111) surfaces. Journal of Physical Chemistry A 1997, 101 (1), 76-82.

59. Olah, G. A.; Liang, G.; Babiak, K. A.; Ford, T. M.; Goff, D. L.; Morgan, T. K.; Murray, R. K., STRUCTURE OF CYCLOPROPYLCARBINYL AND CYCLOBUTYL CATIONS - 8,9-DEHYDRO-2-ADAMANTYL AND 2,5-DEHYDRO-4-PROTOADAMANTYL CATIONS. Journal of the American Chemical Society 1978, 100 (5), $1494-1500$.

60. Marton, D.; Boyd, K. J.; Albayati, A. H.; Todorov, S. S.; Rabalais, J. W., CARBON NITRIDE DEPOSITED USING ENERGETIC SPECIES - A 2-PHASE SYSTEM. Physical Review Letters 1994, 73 (1), 118121.

61. Stöhr, J., NEXAFS Spectroscopy. Springer-Verlag Berlin Heidelberg: 1992; p 404.

62. Morar, J. F.; Himpsel, F. J.; Hollinger, G.; Hughes, G.; Jordan, J. L., OBSERVATION OF A C-1S CORE EXCITON IN DIAMOND. Physical Review Letters 1985, 54 (17), 1960-1963.

63. Himpsel, F. J.; van der Veen, J. F.; Eastman, D. E., Experimental bulk energy bands for diamond using \$h\ensuremath\{\nu\}\$-dependent photoemission. Physical Review B 1980, 22 (4), 1967-1971.

64. Zubavichus, Y.; Shaporenko, A.; Korolkov, V.; Grunze, M.; Zharnikov, M., X-ray Absorption Spectroscopy of the Nucleotide Bases at the Carbon, Nitrogen, and Oxygen K-Edges. The Journal of Physical Chemistry B 2008, 112 (44), 13711-13716.

65. Leinweber, P.; Kruse, J.; Walley, F. L.; Gillespie, A.; Eckhardt, K.-U.; Blyth, R. I. R.; Regier, T., Nitrogen K-edge XANES - an overview of reference compounds used to identify 'unknown' organic nitrogen in environmental samples. Journal of Synchrotron Radiation 2007, 14 (6), 500-511.

66. Bottcher, S.; Vita, H.; Weser, M.; Bisti, F.; Dedkov, Y. S.; Horn, K., Adsorption of Water and Ammonia on Graphene: Evidence for Chemisorption from X-ray Absorption Spectra. Journal of Physical Chemistry Letters 2017, 8 (15), 3668-3672.

67. Reinholdt, P.; Vidal, M. L.; Kongsted, J.; Iannuzzi, M.; Coriani, S.; Odelius, M., Nitrogen K-Edge $\mathrm{X}$-ray Absorption Spectra of Ammonium and Ammonia in Water Solution: Assessing the Performance of Polarizable Embedding Coupled Cluster Methods. The Journal of Physical Chemistry Letters 2021, 12 (36), 8865-8871.

68. Ekimova, M.; Quevedo, W.; Szyc, Ł.; lannuzzi, M.; Wernet, P.; Odelius, M.; Nibbering, E. T. J., Aqueous Solvation of Ammonia and Ammonium: Probing Hydrogen Bond Motifs with FT-IR and Soft X-ray Spectroscopy. Journal of the American Chemical Society 2017, 139 (36), 12773-12783.

69. Titus, C. J.; Baker, M. L.; Lee, S. J.; Cho, H. M.; Doriese, W. B.; Fowler, J. W.; Gaffney, K.; Gard, J. D.; Hilton, G. C.; Kenney, C.; Knight, J.; Li, D. L.; Marks, R.; Minitti, M. P.; Morgan, K. M.; O'Neil, G. C.; Reintsema, C. D.; Schmidt, D. R.; Sokaras, D.; Swetz, D. S.; Ullom, J. N.; Weng, T. C.; Williams, C.; Young, B. A.; Irwin, K. D.; Solomon, E. I.; Nordlund, D., L-edge spectroscopy of dilute, radiation-sensitive systems using a transition-edge-sensor array. Journal of Chemical Physics 2017, 147 (21), 214201.

70. Lee, S. J.; Titus, C. J.; Mori, R. A.; Baker, M. L.; Bennett, D. A.; Cho, H. M.; Doriese, W. B.; Fowler, J. W.; Gaffney, K. J.; Gallo, A.; Gard, J. D.; Hilton, G. C.; Jang, H.; Joe, Y. I.; Kenney, C. J.; Knight, J.; Kroll, T.; Lee, J. S.; Li, D. L.; Lu, D. H.; Marks, R.; Minitti, M. P.; Morgan, K. M.; Ogasawara, H.; O'Neil, G. C.; Reintsema, C. D.; Schmidt, D. R.; Sokaras, D.; Ullom, J. N.; Weng, T. C.; Williams, C.; Young, B. A.; Swetz, D. S.; Irwin, K. D.; Nordlund, D., Soft X-ray spectroscopy with transition-edge sensors at Stanford Synchrotron Radiation Lightsource beamline 10-1. Review of Scientific Instruments 2019, 90 (11), 113101. 71. Ma, Y.; Skytt, P.; Wassdahl, N.; Glans, P.; Mancini, D. C.; Guo, J.; Nordgren, J., CORE EXCITONS AND VIBRONIC COUPLING IN DIAMOND AND GRAPHITE. Physical Review Letters 1993, 71 (22), 3725-3728. 72. Weinhardt, L.; Weigand, M.; Fuchs, O.; Bar, M.; Blum, M.; Denlinger, J. D.; Yang, W.; Umbach, E.; Heske, C., Nuclear dynamics in the core-excited state of aqueous ammonia probed by resonant inelastic soft x-ray scattering. Physical Review B 2011, 84 (10), 104202. 
73. Wang, X.; Hou, Z.; Ikeda, T.; Oshima, M.; Kakimoto, M.-a.; Terakura, K., Theoretical Characterization of X-ray Absorption, Emission, and Photoelectron Spectra of Nitrogen Doped along Graphene Edges. The Journal of Physical Chemistry A 2013, 117 (3), 579-589.

74. Weinhardt, L.; Benkert, A.; Meyer, F.; Blum, M.; Hauschild, D.; Wilks, R. G.; Bar, M.; Yang, W.; Zharnikov, M.; Reinert, F.; Heske, C., Local electronic structure of the peptide bond probed by resonant inelastic soft X-ray scattering. Physical Chemistry Chemical Physics 2019, 21 (24), 13207-13214.

75. Pandey, K. C., NEW DIMERIZED-CHAIN MODEL FOR THE RECONSTRUCTION OF THE DIAMOND (111)-(2X1) SURFACE. Physical Review B 1982, 25 (6), 4338-4341.

76. Sonogashira, K.; Tohda, Y.; Hagihara, N., CONVENIENT SYNTHESIS OF ACETYLENES - CATALYTIC SUBSTITUTIONS OF ACETYLENIC HYDROGEN WITH BROMOALKENES, IODOARENES, AND BROMOPYRIDINES. Tetrahedron Letters 1975, (50), 4467-4470.

77. Liu, W. B.; Li, L.; Li, C. J., Empowering a transition-metal-free coupling between alkyne and alkyl iodide with light in water. Nature Communications 2015, 6 (1), 6526.

78. Weinhardt, L.; Fuchs, O.; Batchelor, D.; Bär, M.; Blum, M.; Denlinger, J. D.; Yang, W.; Schöll, A.; Reinert, F.; Umbach, E.; Heske, C., Electron-hole correlation effects in core-level spectroscopy probed by the resonant inelastic soft x-ray scattering map of C60. The Journal of Chemical Physics 2011, 135 (10), 104705.

79. Müller, T. E.; Hultzsch, K. C.; Yus, M.; Foubelo, F.; Tada, M., Hydroamination: Direct Addition of Amines to Alkenes and Alkynes. Chemical Reviews 2008, 108 (9), 3795-3892.

80. Shearer, J.; Callan, P. E.; Masitas, C. A.; Grapperhaus, C. A., Influence of Sequential Thiolate Oxidation on a Nitrile Hydratase Mimic Probed by Multiedge X-ray Absorption Spectroscopy. Inorganic Chemistry 2012, 51 (11), 6032-6045. 
TOC Graphic

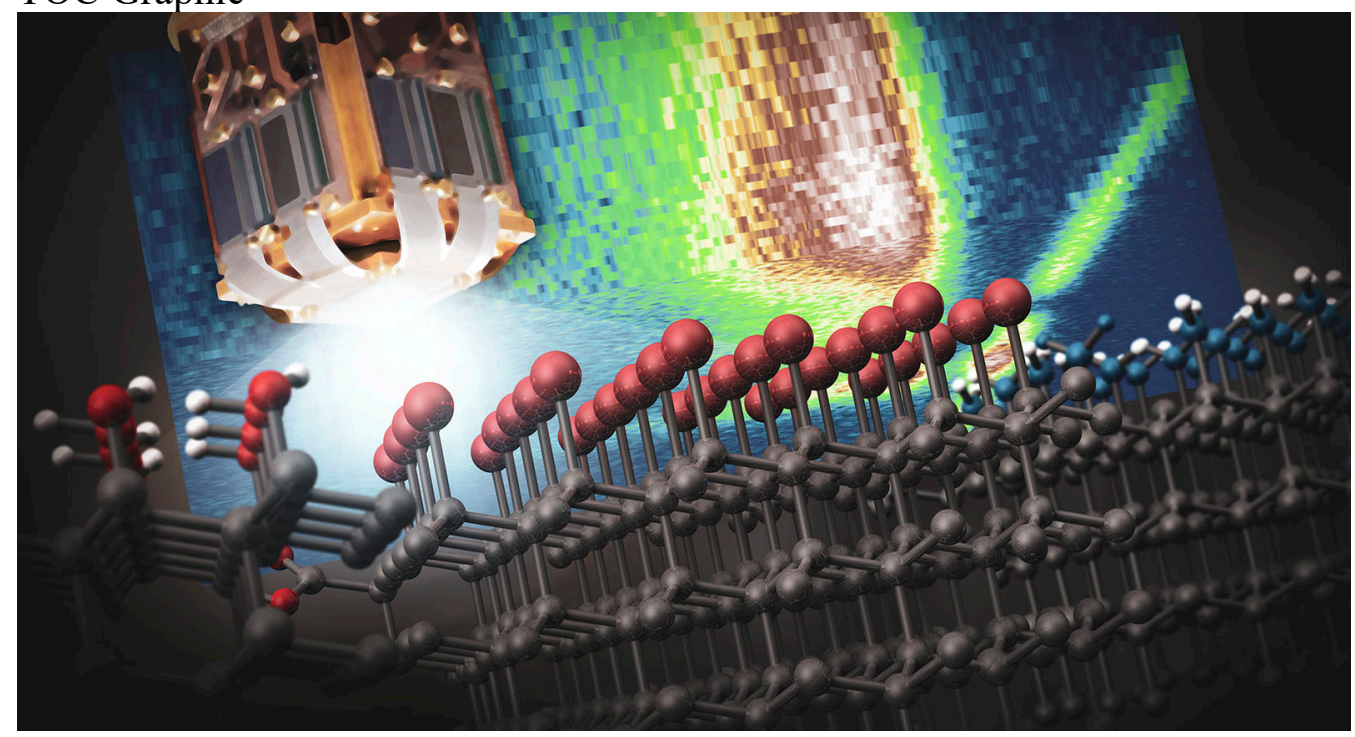

The transition edge sensor (TES) detector, a superconducting X-ray detector housed at the Stanford Synchrotron Radiation Lightsource, probes a diamond surface containing alcohols, bromide and amines and creates a complete energy landscape of the unoccupied and occupied density of states of the quantum nanoprobe.

Keywords: nanodiamond, high-pressure high-temperature diamond, nitrogen vacancy center, and bromine chemistry 